\title{
31P Magic Angle Spinning NMR Spectroscopy of Paramagnetic Rare Earth-Substituted Keggin and Wells-Dawson Solids
}

\author{
Wenlin Huang ${ }^{1}$, Mark Schopfer ${ }^{1}$ Cheng Zhang $^{2}$, Robertha C. Howell ${ }^{2}$, Louis Todaro ${ }^{2}$, Becky $^{*}$ \\ A. $\mathrm{Gee}^{3}$, Lynn C. Francesconi ${ }^{2,}{ }^{,}$, and Tatyana Polenova ${ }^{1,{ }^{*}}$ \\ 1Department of Chemistry and Biochemistry, University of Delaware, Newark, DE 19716 \\ 2Department of Chemistry, City University of New York-Hunter College, 695 Park Avenue, New York, NY \\ 10021 \\ 3Department of Chemistry and Biochemistry, Long Island University-Brooklyn Campus, 1 University Plaza, \\ Brooklyn, NY 11201
}

\section{Abstract}

Paramagnetic rare-earth elements have been examined as NMR structural probes in polyoxoanionic solids, which have a variety of applications as luminescent materials that are usually disordered and therefore intractable by traditional structural methods. Thirteen Keggin and Wells-Dawson polyoxotungstates containing substitutions with lanthanides of different effective magnetic moments have been examined by ${ }^{31} \mathrm{P}$ magic angle spinning NMR spectroscopy. The electron-nuclear dipolar interaction dominating the spinning sideband envelopes is determined by the lanthanide's magnetic moment and was found to be a sensitive probe of the nature of the polyoxoanion, of the positional isomerism, and of the ion stoichiometry. Electron-nuclear dipolar anisotropies computed based on the point-dipole approximation are generally in good agreement with the experimental results. The choice of a specific lanthanide as a structural probe can be tailored to the desired distance range between the phosphorus atoms and the paramagnetic centers to be probed. This approach is expected to be particularly useful in the paramagnetic polyoxoanionic materials lacking long-range order.

\section{Keywords}

solid-state NMR; Magic Angle spinning; MAS; ${ }^{31} \mathrm{P}$; polyoxometalate; POM; lanthanide; rare earth; Keggin; Wells-Dawson; phosphorus; paramagnetic; polyoxoanion; oxotungstate; electron-nuclear dipole-dipole coupling; chemical-shielding anisotropy; X-ray crystallography

\section{Introduction}

Lanthanide-containing solid-state materials have found numerous applications in catalysis, as electroluminescent optical devices and probes, lasers, and luminophores for displays. ${ }^{1,2}$ Many of these materials do not have long-range order in the solid state, and high-resolution structural information cannot be obtained by conventional structural methods. Polyoxometalates are one

\footnotetext{
*To whom the correspondence should be addressed: a) Tatyana Polenova, Department of Chemistry and Biochemistry, University of Delaware, Newark, DE19716, e-mail: tpolenov@udel.edu, Tel. (302) 831-1968, FAX (302) 831-6335; b) Lynn C. Francesconi, Department of Chemistry, Hunter College, 695 Park Avenue, New York, NY 10021, e-mail: lfrances@ @unter.cuny.edu, Phone (212) 772-5353, FAX (212) 772-5332

BRIEFS Rare earth-substituted paramagnetic Keggin and Wells-Dawson oxotungstates have been addressed. The electron-nuclear dipolar coupling tensors are sensitive probe of the mutual arrangement of paramagnetic centers in the crystal lattice. 31P solid-state NMR spectroscopy provides a quick and sensitive probe of the local environment in these solids.
} 
class of attractive frameworks for design of solid-state materials due their ordered geometric structures, diverse electronic properties, and the possibility for incorporation of various metal ions to tune their catalytic, magnetic, electronic or photochemical properties for specific applications. For example, lanthanides can be introduced into the oxoanion core of Keggin and Wells-Dawson compounds in a controlled way to produce structures corresponding to different positional isomers and to different stoichiometries. ${ }^{3-8}$

Indeed, recent investigations have demonstrated that lanthanide-substituted polyoxotungstates prepared via molecular assembly by Langmuir-Blodgett techniques, or fabricated using a variety of techniques as hybrid organic-inorganic functional materials show a broad charge transfer band from the W-O framework or from organic ligands, and effective energy transfer to lanthanide ions. ${ }^{9-18}$ At the same time, crystallographic studies of lanthanide oxopolytungstates have indicated that a polymeric frame network forms in the solids in which the lanthanide ions act as a linker for the construction of 2-D or 3-D networks. ${ }^{19-24}$ These discoveries of the promising luminescent characteristics and of the diverse architectures of lanthanide polyoxometalates establish the groundwork for the design of solid luminescent materials using rare-earth substituted oxotungstates.

Luminescence properties of hybrid organic/inorganic thin films are known to differ from those of the neat polyoxometalate compounds. ${ }^{11,25}$ The local structure of the lanthanide polyoxoanion may be altered, possibly because of the oxoanion-organic matrix and cation interactions. The local geometry of polyoxoanions in thin films and the nature of their interactions with the organic matrix and with counter ions are not understood. Lack of longrange order in these hybrid materials prevents their analysis by X-ray crystallography, while fluorescence and luminescence spectra lack the required site resolution. Characterization of the local geometry is necessary to be able to design luminescent polyoxometalate materials with desired characteristics, and therefore alternative probes that would possess the necessary site resolution are needed.

Additionally and importantly, polyoxoanionic solids represent excellent models of disordered metal oxide-based materials. ${ }^{26-29}$ The structural and electronic diversity of Keggin and WellsDawson polyoxometalates discussed above, in conjunction with the availability of highresolution X-ray data for the crystalline representatives of these families have already yielded important insights into how to tune the macroscopic materials properties via controlled substitution with different elements. $., 7,21,30-32$ Furthermore, crystalline polyoxometalate solids are indispensable for design and testing of novel probes for structural studies of disordered materials.

Our recent work explored the utility of Eu(III) as a paramagnetic NMR structural probe in europium-substituted Keggin and Wells-Dawson solids. ${ }^{33,34}$ The strong anisotropic electronnuclear dipolar interaction was found to dominate the ${ }^{31} \mathrm{P}$ magic angle spinning (MAS) spectra in these compounds, and to be a useful and quantitative probe of local geometry. Other nuclear probes (e.g., ${ }^{13} \mathrm{C},{ }^{1} \mathrm{H},{ }^{2} \mathrm{H},{ }^{6} \mathrm{Li},{ }^{7} \mathrm{Li}$ ) have also been reported to elicit information on local structure in different inorganic solids. ${ }^{35-43}$

In the present study, we identify the general utility of paramagnetic lanthanides as local geometry probes in an extensive series of oxotungstates substituted with different rare earth elements, and of the two most prevalent structural families, Keggin and Wells-Dawson. The geometric information is extracted by analysis of anisotropic electron-nuclear dipolar interaction between ${ }^{31} \mathrm{P}$ (used as a nuclear reporter) and the paramagnetic rare-earth centers. This interaction is measured experimentally by the ${ }^{31} \mathrm{P}$ MAS NMR spectroscopy. We examine the magnitude of the electron-nuclear dipolar coupling as a function of the lanthanide magnetic moment, in different positional isomers, and in solids of different stoichiometries. Our results 
indicate that the electron-nuclear dipolar tensor, which is a distance-dependent quantity, reports on the mutual arrangements of the paramagnetic centers in the crystal lattice of the polyoxoanionic solids. These in turn are dictated by the anion stoichiometry and by which specific positional isomer is addressed. Furthermore, a specific paramagnetic lanthanide can be chosen as a structural probe based on its effective magnetic moment, which is an inherent property of a particular lanthanide element. The lanthanide's effective magnetic moment determines the strength of the electron-nuclear dipolar interaction (that is also distance dependent), and thus the choice of a lanthanide possessing a particular magnetic moment as a structural reporter can serve to tune the electron-nuclear dipolar interaction to the specific phosphorus-lanthanide distance range to be probed. ${ }^{31} \mathrm{P}$ solid-state NMR spectroscopy thus provides a sensitive probe of local environments in these solids. This approach is applicable to nuclei other than ${ }^{31} \mathrm{P}$ and inorganic solids other than polyoxometalates, and we anticipate that it will be particularly useful for noncrystalline materials lacking long-range order.

\section{Experimental Section}

\section{Materials and Syntheses}

All chemicals were obtained from Aldrich or Fisher and used without further purification: sodium tungstate dihydrate $\left(\mathrm{Na}_{2} \mathrm{WO}_{4} \cdot 2 \mathrm{H}_{2} \mathrm{O}\right)$, lanthanide (III) chlorides hydrates $\left(\mathrm{LnCl}_{3} \cdot x \mathrm{H}_{2} \mathrm{O}, \mathrm{Ln}=\mathrm{La}, \mathrm{Ce}, \mathrm{Pr}, \mathrm{Nd}, \mathrm{Eu}, \mathrm{Gd}, \mathrm{Tb}, \mathrm{Dy}, \mathrm{Er}, \mathrm{Lu}\right.$ and $\left.\mathrm{Y}\right)$ were purchased from Aldrich Chemicals. Hydrochloric acid, lithium acetate, potassium chloride, ammonium chloride, phosphoric acid (85\%), sulfuric acid, and bromine were purchased from Fisher Scientific.

The rare earth-substituted polyoxometalate complexes include two types of Wells-Dawson solids as well as a set of tetrameric Keggin oxotungstates with trivalent lanthanide ions incorporated into the oxoanion core: $\mathrm{K}_{14}\left(\mathrm{H}_{3} \mathrm{O}\right)_{3}\left[\mathrm{La}\left(\alpha_{1}-\mathrm{P}_{2} \mathrm{~W}_{17} \mathrm{O}_{61}\right)_{2}\right] \cdot 4 \mathrm{KCl} \cdot 64 \mathrm{H}_{2} \mathrm{O}(\mathbf{I})$, $\mathrm{K}_{14}\left(\mathrm{H}_{3} \mathrm{O}\right)_{3}\left[\mathrm{Nd}\left(\alpha_{1}-\mathrm{P}_{2} \mathrm{~W}_{17} \mathrm{O}_{61}\right)_{2}\right] \cdot 4 \mathrm{KCl} \cdot 64 \mathrm{H}_{2} \mathrm{O}(\mathbf{I I}), \mathrm{K}_{14}\left(\mathrm{H}_{3} \mathrm{O}\right)_{3}\left[\operatorname{Er}\left(\alpha_{1}-\mathrm{P}_{2} \mathrm{~W}_{17} \mathrm{O}_{61}\right)_{2}\right] \cdot 4 \mathrm{KCl}$ $\cdot 64 \mathrm{H}_{2} \mathrm{O}(\mathbf{I I I}), \mathrm{K}_{13}\left(\mathrm{H}_{3} \mathrm{O}\right)\left[\mathrm{Ce}\left(\mathrm{H}_{2} \mathrm{O}\right)_{4}\left(\alpha_{2}-\mathrm{P}_{2} \mathrm{~W}_{17} \mathrm{O}_{61}\right)\right]_{2} \cdot 2 \mathrm{KCl} \cdot \mathrm{nH}_{2} \mathrm{O}(\mathbf{I V}), \mathrm{K}_{13}\left(\mathrm{H}_{3} \mathrm{O}\right)[\mathrm{Nd}$ $\left.\left(\mathrm{H}_{2} \mathrm{O}\right)_{3}\left(\alpha_{2}-\mathrm{P}_{2} \mathrm{~W}_{17} \mathrm{O}_{61}\right)\right]_{2} \cdot 2 \mathrm{KCl} \cdot \mathrm{nH}_{2} \mathrm{O}(\mathrm{V}), \mathrm{K}_{13}\left(\mathrm{H}_{3} \mathrm{O}\right)\left[\mathrm{Pr}\left(\mathrm{H}_{2} \mathrm{O}\right)_{4}\left(\alpha_{2}-\mathrm{P}_{2} \mathrm{~W}_{17} \mathrm{O}_{61}\right)\right]_{2} \cdot 2 \mathrm{KCl} \cdot \mathrm{nH}_{2} \mathrm{O}$ $(\mathbf{V I})$, and $\mathrm{K}_{13}\left(\mathrm{H}_{3} \mathrm{O}\right)\left[\mathrm{Lu}\left(\mathrm{H}_{2} \mathrm{O}\right)_{3}\left(\alpha_{2}-\mathrm{P}_{2} \mathrm{~W}_{17} \mathrm{O}_{61}\right)\right]_{2} \cdot 2 \mathrm{KCl} \cdot \mathrm{nH}_{2} \mathrm{O}$ (VII). The rare earth substituted tetrameric Keggin solids include $\mathrm{Na}_{8} \mathrm{~K}_{5}\left(\mathrm{H}_{3} \mathrm{O}\right)_{19} \mathrm{Cl}_{10}\left[\left(\mathrm{Y}_{2} \mathrm{PW}_{10} \mathrm{O}_{38}\right)_{4} \mathrm{~W}_{3} \mathrm{O}_{8}\left(\mathrm{H}_{2} \mathrm{O}\right)_{2}(\mathrm{OH})_{4}\right]$. $\left.\left(\mathrm{CH}_{3} \mathrm{OH}\right) \cdot 32 \mathrm{H}_{2} \mathrm{O}(\mathrm{VIII}), \mathrm{Na}_{8} \mathrm{~K}_{5}\left(\mathrm{H}_{3} \mathrm{O}\right)_{19} \mathrm{Cl}_{10}\left[\left(\mathrm{Er}_{2} \mathrm{PW}_{10} \mathrm{O}_{38}\right)_{4} \mathrm{~W}_{3} \mathrm{O}_{8}\left(\mathrm{H}_{2} \mathrm{O}\right)_{2}(\mathrm{OH})_{4}\right)\right] \cdot\left(\mathrm{CH}_{3} \mathrm{OH}\right)$ $\cdot 32 \mathrm{H}_{2} \mathrm{O}(\mathbf{I X}),\left(\mathrm{NH}_{4}\right)_{22}\left[\left(\mathrm{Eu}_{2} \mathrm{PW}_{10} \mathrm{O}_{38}\right)_{4}\left(\mathrm{~W}_{3} \mathrm{O}_{8}\left(\mathrm{H}_{2} \mathrm{O}\right)_{2}(\mathrm{OH})_{4}\right)\right] \cdot 44 \mathrm{H}_{2} \mathrm{O}(\mathbf{X})$, $\left.\mathrm{Na}_{8} \mathrm{~K}_{5}\left(\mathrm{H}_{3} \mathrm{O}\right)_{19} \mathrm{Cl}_{10}\left[\left(\mathrm{Gd}_{2} \mathrm{PW}_{10} \mathrm{O}_{38}\right)_{4} \mathrm{~W}_{3} \mathrm{O}_{8}\left(\mathrm{H}_{2} \mathrm{O}\right)_{2}(\mathrm{OH})_{4}\right)\right] \cdot\left(\mathrm{CH}_{3} \mathrm{OH}\right) \cdot 32 \mathrm{H}_{2} \mathrm{O}(\mathbf{X I})$, $\left.\mathrm{Na}_{8} \mathrm{~K}_{5}\left(\mathrm{H}_{3} \mathrm{O}\right)_{19} \mathrm{Cl}_{10}\left[\left(\mathrm{~Tb}_{2} \mathrm{PW}_{10} \mathrm{O}_{38}\right)_{4} \mathrm{~W}_{3} \mathrm{O}_{8}\left(\mathrm{H}_{2} \mathrm{O}\right)_{2}(\mathrm{OH})_{4}\right)\right] \cdot\left(\mathrm{CH}_{3} \mathrm{OH}\right) \cdot 32 \mathrm{H}_{2} \mathrm{O}$ (XII), and $\left.\mathrm{Na}_{8} \mathrm{~K}_{5}\left(\mathrm{H}_{3} \mathrm{O}\right)_{19} \mathrm{Cl}_{10}\left[\left(\mathrm{Dy}_{2} \mathrm{PW}_{10} \mathrm{O}_{38}\right)_{4} \mathrm{~W}_{3} \mathrm{O}_{8}\left(\mathrm{H}_{2} \mathrm{O}\right)_{2}(\mathrm{OH})_{4}\right)\right] \cdot\left(\mathrm{CH}_{3} \mathrm{OH}\right) \cdot 32 \mathrm{H}_{2} \mathrm{O}$ (XIII).

Synthesis of these compounds and their X-ray crystal structures (except for the $\mathrm{X}$-ray structure of IX reported herein) have been reported recently. $3,6,7,44$ The schematic representations of the individual anions are shown in Figure 1.

\section{Single-Crystal X-ray Diffraction of $\left.\mathrm{Na}_{8} \mathrm{~K}_{5}\left(\mathrm{H}_{3} \mathrm{O}\right)_{19} \mathrm{Cl}_{10}\left[\left(\mathrm{Er}_{2} \mathrm{PW}_{10} \mathrm{O}_{38}\right)_{4} \mathrm{~W}_{3} \mathrm{O}_{8}\left(\mathrm{H}_{2} \mathrm{O}\right)_{2}(\mathrm{OH})_{4}\right)\right] \cdot\left(\mathrm{CH}_{3} \mathrm{OH}\right) \cdot 32 \mathrm{H}_{2} \mathrm{O}(\mathrm{IX})$-The} intensity data for $\mathbf{I X}$ were measured on an Bruker-Nonius KappaCCD diffractometer (graphitemonochromated Mo $K \alpha$ radiation, $\lambda=0.71073 \AA$ $\rho$ - $\omega$ scans) at 100 (1) $\mathrm{K}$. The data were corrected for absorption. The crystal of $\mathbf{I X}$, with approximate dimensions $0.16 \times 0.20 \times 0.36$ $\mathrm{mm}$, were monoclinic with space group $C 2 / c$. The final unit-cell constants of IX were $a=$ 22.090(4), $b=34.128(7), c=26.569(5) \AA, \beta=96.11(3)^{\circ}, V=19916(17) \AA^{3}, Z=4, \rho=4.579$ $\mathrm{g} \mathrm{cm}^{-1}, \mu=28.46 \mathrm{~mm}^{-1}$, formula weight $=13730.34$. The structure of IX was solved with SHELXS-97 and refined by full-matrix least squares on $F^{2}$ with SHELXL-97. The hydrogen atoms of the solvent atoms were not included in the structure-factor calculations. Some of the water molecules reported in the formula may actually be hydroxyl groups. The final discrepancy indices for the 22877 reflections $\left(\theta<27.45^{\circ}\right)$ were $R=0.0621$ (calculated on $F$ ) 
and $R_{w}=0.1336$ (calculated on $F^{2}$ ) with 1336 parameters varied. The final difference map peaks $\left(<4.3 \mathrm{e}^{-3}\right)$ were near the tungsten and erbium atoms. The summary of crystal structure and structure refinement parameters is presented in Table $1 \mathrm{~S}$ of the supporting information.

Solid-State NMR Spectroscopy- ${ }^{31} \mathrm{P}$ solid-state NMR spectra were acquired at 162.028 $\mathrm{MHz}(9.4 \mathrm{~T}$ ) on a Tecmag Discovery spectrometer using a $4 \mathrm{~mm}$ Varian T3 probe. $30-40 \mathrm{mg}$ of sample were packed into zirconium oxide rotors for data collection. The magic angle was adjusted using $\mathrm{NaNO}_{3}$ (by detecting the ${ }^{23} \mathrm{Na}$ MAS signal). ${ }^{31} \mathrm{P}$ NMR spectra were collected at several different spinning frequencies ranging from 1 to $17 \mathrm{kHz}$. A single $3 \mu$ s pulse $\left(\gamma H_{1} / 2 \pi=83.3 \mathrm{kHz}\right)$ was employed; the pulse delays of $3 \mathrm{~s}$ and $60 \mathrm{~s}$ were used for paramagnetic and diamagnetic lanthanide compounds, respectively. The MAS spinning frequency was controlled to within $+/-2 \mathrm{~Hz}$. A total of 1024 complex data points were acquired. The data were processed by Fourier transformation and baseline correction using the MestRe-C23 NMR data processing software. ${ }^{45}$ The spectra of Er-substituted compounds III and IX were processed with linear prediction of the first 40-50 points of the FID, followed by Fourier transformation and baseline correction. Isotropic chemical shifts are reported with respect to the $85 \% \mathrm{H}_{3} \mathrm{PO}_{4}$ used as an external reference.

Simulations of the NMR Spectra-Numerical simulations of the experimental ${ }^{31} \mathrm{P}$ solidstate NMR spectra were performed on a $1.1 \mathrm{GHz}$ Pentium-4 PC under the Linux environment using the SIMPSON software package. ${ }^{46}$ The independent parameters describing the CSA tensor anisotropies and calculations of the shielding tensors were also performed using the Herzfeld-Berger algorithm ${ }^{47}$ implemented in the HBA 1.4.4 program. 48

Calculation of Electron-Nuclear Dipolar Coupling Tensors-The dipolar coupling tensors between the phosphorus atom and the paramagnetic nuclei in II-V, IX and $\mathbf{X}$ were calculated as described in our recent report, ${ }^{33}$ using a home-written program in Mathematica 5.0 (Wolfram, Inc.). The experimental crystallographic coordinates and effective magnetic moments were utilized. For the sake of clarity, here we present a brief summary of the salient points considered in the calculations.

The Hamiltonian for a spin- $1 / 2$ nucleus in a paramagnetic system is

$$
H=H_{\text {Zeeman }}+H_{R F}+H_{D I P}^{\text {paramagn }}+H_{C S A}+H_{F C}+H_{D I P}
$$

The terms in the Hamiltonian represent the Zeeman, the radiofrequency field, the electronnuclear dipolar interaction, the chemical shift anisotropy, the Fermi contact shift, and the nuclear dipolar interaction.

The electron-nuclear dipolar interaction is expressed as

$$
H_{D I P}^{\text {paramagn }}=\frac{\mu_{0}}{4 \pi} \bar{\mu}_{e} \cdot \tilde{D}_{e n} \cdot \mu_{n}
$$

where $\mu_{0}$ is the magnetic permeability, $\bar{\mu}_{e}$ is the thermally averaged electronic magnetic moment, $\tilde{D}_{e n}$ is the electron-nuclear dipolar coupling tensor, and $\mu_{n}$ is the nuclear magnetic moment.

The electron-nuclear dipolar coupling tensor $\tilde{D}_{e n}$ is expressed in a matrix representation: ${ }^{41}$

$$
\tilde{D}_{e n}=\frac{1}{r^{3}}\left(\delta_{\alpha \beta}-3 e_{\alpha} e_{\beta}\right)
$$

$r$ is the electron-nuclear distance, $\delta_{\alpha \beta}$ is the Kronecker delta, $e_{\alpha}$ and $e_{\beta}$ are the (x,y,z) components of the electron-nuclear dipolar vector. 
In the rare-earth substituted polyoxoanionic solids under investigation, the electron-nuclear dipolar coupling matrices arising from the interactions of ${ }^{31} \mathrm{P}$ with multiple rare-earth sites, have to be considered. It has been shown previously 38,41 that to a good approximation the local fields on the nucleus are independent contributions of the individual electrons. Thus the total electron-nuclear dipolar Hamiltonian can be obtained by summing up the dipolar matrices corresponding to the individual electron-nuclear spin pairs:

$$
H_{D I P}^{\text {paramagan }}=\frac{\mu_{0}}{4 \pi} \bar{\mu}_{e} \cdot\left(\sum_{i} \tilde{D}_{e n, i}\right) \cdot \mu_{n}
$$

The summed dipolar coupling tensor is transformed to its principal axes system by diagonalization of the corresponding matrix, to obtain its eigenvalues $\delta_{x x}, \delta_{y y}, \delta_{z z}$, where by convention $\left|\delta_{z z}-\delta_{i s o}\right| \geq\left|\delta_{x x}-\delta_{i s o}\right| \geq\left|\delta_{y y}-\delta_{i s o}\right|$. The principal components are subsequently defined as

$$
\begin{gathered}
\Delta \delta=\delta_{z z}-1 / 2\left(\delta_{x x}+\delta_{y y}\right) \\
\eta=\frac{\delta_{y y}-\delta_{x x}}{\delta_{z z}-\delta_{i s o}} \\
\delta_{i s o}=1 / 3\left(\delta_{x x}+\delta_{y y}+\delta_{z z}\right)
\end{gathered}
$$

$\delta_{i s o}$ is the isotropic shift; $\Delta \delta$ is the electron-nuclear dipolar anisotropy determining the breadth of the dipolar coupling tensor. $\eta$ is the asymmetry parameter of the dipolar coupling tensor characterizing the deviation of the dipolar tensor from the axial symmetry.

It is worth noting that for ${ }^{31} \mathrm{P}$ nuclei with relatively weak couplings to the paramagnetic center (s), the contribution of the ${ }^{31} \mathrm{P}$ chemical shielding anisotropy cannot be neglected. In this case, the effective anisotropy is a sum of the electron-nuclear dipolar and the CSA tensors. The experimental measurements will yield this combined interaction rather than the electronnuclear dipolar anisotropy alone.

\section{Results and Discussion}

\section{${ }^{31} \mathrm{P}$ MAS NMR Spectra of Diamagnetic and Paramagnetic Rare Earth $\alpha_{1}$-Substituted Wells- Dawson Polyoxometalate Solids}

The $\alpha_{1}$-substituted Wells-Dawson polyoxometalate solids are 1:2 Ln: $\left(\alpha_{1}-\mathrm{P}_{2} \mathrm{~W}_{17} \mathrm{O}_{61}\right)$ species wherein one $\mathrm{Ln}(\mathrm{III})$ is complexed to the four oxygen atoms of each of the two lacunary $\mathrm{P}_{2} \mathrm{~W}_{17} \mathrm{O}_{61}{ }^{10-}$ ions (i.e., ions with one or more vacant $\mathrm{W}$ site(s) in the core, where substitutions with other atoms can occur, as illustrated in Figure $1 \mathrm{~b}$ ). The ${ }^{31}$ P MAS NMR spectra of 1:2 Ln: $\left(\alpha_{1}-\mathrm{P}_{2} \mathrm{~W}_{17} \mathrm{O}_{61}\right)(\mathrm{Ln}=\mathrm{La}, \mathrm{Nd}$, and Er) acquired at a spinning frequency of $10 \mathrm{kHz}$ are presented in Figure 2, together with the spectrum of the corresponding 1:2 Eu: $\left(\alpha_{1}-\mathrm{P}_{2} \mathrm{~W}_{17} \mathrm{O}_{61}\right)$ for comparison. The 1:2 La: $\left(\alpha_{1}-\mathrm{P}_{2} \mathrm{~W}_{17} \mathrm{O}_{61}\right)(\mathbf{I})$ gives rise to two ${ }^{31} \mathrm{P}$ isotropic resonances shown in the inset of Figure 2a, indicating a small chemical shielding anisotropy present in this compound. Lanthanum (III) ion is diamagnetic (Table 1) with electron configuration of [Xe] $4 \mathrm{f}^{0}$; the corresponding Wells-Dawson compound is diamagnetic as well. Numerical analysis of the spinning sidebands of $\mathbf{I}$ at low spinning frequencies yields chemical shielding anisotropies of $31.1 \mathrm{ppm}(\mathrm{P} 1)$ and $13.8 \mathrm{ppm}(\mathrm{P} 2)$.

Both $\mathrm{Nd}^{3+}$ and $\mathrm{Er}^{3+}$ ions have 3 unpaired electrons in their $4 \mathrm{f}$ orbitals, and therefore the $\mathrm{Nd}^{3+}$ and $\mathrm{Er}^{3+}$ complexes are expected to be paramagnetic. Indeed, the ${ }^{31} \mathrm{P}$ spectrum of 1:2 $\mathrm{Nd}:\left(\alpha_{1}-\mathrm{P}_{2} \mathrm{~W}_{17} \mathrm{O}_{61}\right)(\mathbf{I I})$ exhibits a large manifold of spinning sidebands spanning ca $400 \mathrm{ppm}$ in Figure $2 \mathrm{~b}$, and revealing that the electron-nuclear dipolar interaction between $\mathrm{Nd}^{3+}$ ion and 
phosphorus atom dominates the NMR spectrum in this species. Numerical analysis of the spinning sidebands of II yields effective anisotropies of $148.1 \mathrm{ppm}(\mathrm{P} 1)$ and $72.4 \mathrm{ppm}(\mathrm{P} 2)$. The ${ }^{31} \mathrm{P}$ spectrum of 1:2 $\mathrm{Er}:\left(\alpha_{1}-\mathrm{P}_{2} \mathrm{~W}_{17} \mathrm{O}_{61}\right)$ (III) shows two sets of spinning sidebands both exhibiting much broader spectral envelopes compared with the $\mathrm{Nd}^{3+}$ spectra, as shown in Figure 2c-e (the individual envelopes shown with red and blue markers). The broader set of spinning sidebands has lower signal-to-noise ratio. We attribute this spinning sideband envelope to the phosphorus site closest to the paramagnetic center (arbitrarily designated as P1), and the narrower envelope-to the distant phosphorus site (arbitrarily designated as P2). Due to the low signal-to-noise ratio in the P1 site spectrum, its quantitative analysis to extract the anisotropic NMR observables was not possible. We therefore focus our attention to the P2 site spectra. The spinning sidebands for this site span ca $1000 \mathrm{ppm}$, which is much larger than in the $\mathrm{Nd}^{3+}$ and $\mathrm{Eu}^{3+}$ Wells-Dawson complexes, reflecting the strong electron-nuclear dipolar coupling in this species. The dipolar anisotropy extracted from the numerical analysis of the spectra of the P2 phosphorus site in III is $449.4 \mathrm{ppm}$. According to Equation 4, the electronnuclear dipolar anisotropy is determined by the effective magnetic moment and by the geometry of the paramagnetic centers around the ${ }^{31} \mathrm{P}$ site. As illustrated in Table 1, the effective magnetic moment of $\mathrm{Er}^{3+}$ is $9.6 \mu_{\mathrm{B}}$ (Bohr magnetons), being the largest among lanthanides. Closer inspection of the X-ray structures of II and III reported earlier ${ }^{7}$ and displayed in Figure 3 and 4, respectively, shows that the positions of lanthanide ions with respect to the phosphorus sites in the crystal lattices are similar in these two compounds, indicating that as expected, the effective magnetic moments have dominant effect on the dipolar anisotropies in these lanthanide complexes.

\section{P MAS NMR Spectra of Diamagnetic and Paramagnetic Rare Earth-Substituted Wells- Dawson Polyoxometalate Solids of 2:2 Ln:POM Stoichiometry}

The $\alpha_{2}$-substituted Wells-Dawson polyoxometalate solids are 2:2 Ln: $\left(\alpha_{2}-\mathrm{P}_{2} \mathrm{~W}_{17} \mathrm{O}_{61}\right)$ species wherein two $\mathrm{Ln}$ (III) are complexed to the four oxygen atoms of each of the two lacunary $\mathrm{P}_{2} \mathrm{~W}_{17} \mathrm{O}_{61}{ }^{10-}$ ions (illustrated in Figure 1c and $\left.1 \mathrm{~d}\right)$. There are differences in the 2:2 $\mathrm{Ln}:\left(\alpha_{2}-\right.$ $\mathrm{P}_{2} \mathrm{~W}_{17} \mathrm{O}_{61}$ ) species as the lanthanide series is traversed. The early lanthanides $\mathrm{La}, \mathrm{Ce}, \mathrm{Pr}$ form a "cap to cap" structure (Figure 1c) whereas the later lanthanides (Nd, Eu, Lu) form a "cap to belt" structure (Figure 1d). This structural change accommodates the coordination environments for the early ( 9 coordinate) and later ( 8 coordinate) lanthanides. ${ }^{6,44}$ The ${ }^{31} \mathrm{P}$ spectra of 2:2 Ln: $\left(\alpha_{2}-\mathrm{P}_{2} \mathrm{~W}_{17} \mathrm{O}_{61}\right)(\mathrm{Ln}=\mathrm{Ce}, \mathrm{Pr}, \mathrm{Nd}$, and $\mathrm{Lu})$ Wells-Dawson complexes acquired at a spinning frequency of $5 \mathrm{kHz}$ are shown in Figure $5 . \mathrm{Lu}^{3+}$ with electron configuration $4 \mathrm{f}^{14}$, is a diamagnetic ion, thus the ${ }^{31} \mathrm{P}$ spectrum of $\mathrm{Lu}:\left(\alpha_{2}-\mathrm{P}_{2} \mathrm{~W}_{17} \mathrm{O}_{61}\right)(\mathbf{X})$, as expected, shows two isotropic resonances at high spinning frequency as the chemical shift anisotropy is relatively small and averaged out. The paramagnetic $\mathrm{Ce}^{3+}, \mathrm{Pr}^{3+}$ and $\mathrm{Nd}^{3+}$ Wells-Dawson complexes exhibit large spinning sideband manifolds in the ${ }^{31} \mathrm{P}$ spectra because of the dominant electron-nuclear dipolar interactions. The ${ }^{31} \mathrm{P}$ spectra of $2: 2 \mathrm{Nd}:\left(\alpha_{2}-\mathrm{P}_{2} \mathrm{~W}_{17} \mathrm{O}_{61}\right)(\mathbf{V})$ and $\mathrm{Pr}$ : $\left(\alpha_{2}-\mathrm{P}_{2} \mathrm{~W}_{17} \mathrm{O}_{61}\right)(\mathbf{V I})$ display similar spectral envelope widths, reflecting the fact that these two compounds have similar electron-nuclear dipolar interactions. Numerical analysis of the spectra yielded the effective anisotropies for $\mathbf{V}$ of $166.9 \mathrm{ppm}(\mathrm{P} 1)$ and $65.6 \mathrm{ppm}(\mathrm{P} 2)$, whereas those for VI were $174.5 \mathrm{ppm}(\mathrm{P} 1)$ and $76.5 \mathrm{ppm}(\mathrm{P} 2)$.

\section{${ }^{31}$ P MAS NMR Spectra of Diamagnetic and Paramagnetic Rare Earth-Substituted Keggin Polyoxometalate Solids}

The rare earth-substituted Keggin polyoxometalate solids are assemblies of four di-vacant Keggin fragments tied together by eight Ln(III) ions with two Ln(III) ions substituted for two $\mathrm{W}=\mathrm{O}$ units in each of the four di-vacant Keggin ions. In Figure 6, the ${ }^{31} \mathrm{P}$ spectra (collected at the MAS frequency of $15 \mathrm{kHz}$ ) of these tetrameric Keggin oxotungstates with different lanthanides incorporated ( $\mathrm{Ln}=\mathrm{Y}, \mathrm{Eu}$ and $\mathrm{Er})$ are compared. We note that the NMR parameters for the tetrameric Eu complex were presented in our recent report, ${ }^{33}$ and we are illustrating 
the spectrum of this compound here solely for comparison of the spectroscopic parameters across the lanthanide series under investigation. The spectral envelope widths are a function of the effective magnetic moment in this series, as expected. The diamagnetic yttrium complex (VIII) exhibits two isotropic resonances in the ${ }^{31} \mathrm{P}$ spectrum but no anisotropic spinning sidebands, as anticipated. The erbium complex (IX) shows the largest envelope width; in fact, this is the broadest ${ }^{31} \mathrm{P}$ spectrum we have observed in any lanthanide polyoxotungstate under investigation. Only one set of spinning sidebands was detected in this species with a span of more than $2500 \mathrm{ppm}$. The analysis of the sideband pattern of IX yields the effective anisotropy of $1363.5 \mathrm{ppm}$, much larger than the anisotropy in the Eu tetrameric complex $(\mathbf{X})$, as expected based on the effective electronic magnetic moments of 3.24 and $9.6 \mu \mathrm{B}$ for $\mathrm{Eu}$ and $\mathrm{Er}$, respectively.

Interestingly, we could not detect ${ }^{31} \mathrm{P}$ NMR signal in the Gd-, Dy- and Tb-substituted tetrameric Keggin solids XI, XII, and XIII. These three lanthanides have very large magnetic moments (7.94, 9.0 and $10.6 \mu_{\mathrm{B}}$, respectively), and we attribute the lack of signal to very efficient electron-nuclear dipolar relaxation resulting in short $\mathrm{T}_{2}$ times and broadening of the resonances beyond detection. One possibility is that the crystal packing in these complexes is different enough, so that these short $\mathrm{T}_{2}$ times and line broadening of the lines beyond detection in these compounds might be the result of intermolecular interactions. In this regard it would be interesting in the future to address the dilute versions of these solids where $10-20 \%$ of the paramagnetically-substituted complex would be co-dissolved and co-precipitated with the corresponding diamagnetically-substituted compound. These studies are beyond the scope of the current manuscript. In this context it is surprising that the ${ }^{31} \mathrm{P}$ signal in the Er-substituted Keggin tetrameric solid IX could be seen.

\section{P Isotropic Chemical Shifts in the Rare-Earth-Substituted Polyoxometalate Solids}

The observed isotropic shifts of the ${ }^{31} \mathrm{P}$ nuclei in the lanthanide Wells-Dawson and Keggin complexes are compiled in Table 2. In the Wells-Dawson and Keggin complexes, the two nonequivalent phosphorus atoms are expected to give rise to distinct chemical shifts. However, a single spinning sideband manifold was observed in the spectra of IX, inconsistent with its Xray structure (illustrated in Figure 7). We note that the individual spinning sidebands in the spectra of the two Er-substituted complexes under investigation are quite broad (15 ppm for III, $24 \mathrm{ppm}$ for IX), suggesting the chemical shift overlap in IX. We attribute the broader lines in these two complexes to the more efficient electron-nuclear dipolar relaxation due to the 3fold greater effective electronic magnetic moment of Er. In III, we could not determine the isotropic chemical shift of the P1 site because of the partial overlap of its spinning sideband manifold with that of the P2 site. For VIII, two distinct isotropic peaks of equal intensities were observed. In $\mathbf{X}$ each of the four phosphorus atoms has a different isotropic shift, consistent with the monoclinic space group P-1 of this solid. ${ }^{33}$

Surprisingly, in the majority of Wells-Dawson compounds under investigation the P2 site is more shielded, except for the Nd-substituted II and $\mathbf{V}$. It is also interesting to note that contrary to the Wells-Dawson compounds I-VII, and to the diamagnetic Y-substituted tetrameric solid VIII, the phosphorus resonances in the paramagnetic tetrameric Er and Eu complexes IX and $\mathbf{X}$ are strongly deshielded with respect to the chemical shift standard. In order to understand the overall trends in the isotropic chemical shifts, quantum mechanical calculations of chemical shielding anisotropy in the compounds addressed in this work would be necessary; these studies are beyond the scope of the present manuscript. 


\section{Calculations of the Paramagnetic Dipolar Coupling in Crystallographically Characterized Rare Earth-Substituted Polyoxometalate Solids}

We calculated the electron-nuclear dipolar tensors for II, III, IV, V, and IX based on their crystallographic structures $3,6,7,44$ shown in Figures 3, 4, 8, 9, and 7 (respectively) and following the procedure described in the experimental section and in our previous report. ${ }^{33}$ Due to the lack of experimental values for the effective magnetic moments in these compounds, in the calculations we utilized the magnetic moments of the corresponding free ions shown in Table 1. Electron-nuclear dipolar matrices were calculated by including the lanthanide sites that are within $100 \AA$ of the phosphorus atom. We note that convergence of these calculations is directly related to the effective magnetic moment of the paramagnetic rare earth atom: for larger magnetic moments the calculations have to include more distant paramagnetic sites (illustrated in Figure $2 \mathrm{~S}$ of the Supporting Information). We found that in the compounds under investigation calculations taking into account the paramagnetic sites within $100 \AA$ converge fully for all lanthanides. The calculated NMR parameters are reported in Table 3.

Analysis of the results reveals a strong correlation between the experimental and calculated $\Delta \delta$ (illustrated in Figure 10a). The experimental and calculated values agree within 6-13\% for the P1 sites in all compounds, except for the Ce-substituted Wells-Dawson solid IV, and the Er-substituted tetrameric Keggin solid IX. In IV, we attribute the discrepancies between the experiment and calculations to the partial overlap of the spinning sideband patterns corresponding to the P1 and P2 sites. Due to this overlap, the sideband intensities are not clearly defined, and the accurate values of the tensor components could not be extracted. In IX, the disagreement might be due to the differences in the effective magnetic moment for the free $\mathrm{Er}^{3+}$ ion and that substituted into the polyoxoanion core. Indeed, our recent studies addressing Eu-substituted Keggin compounds revealed that the effective experimentally measured magnetic moments can deviate by $15 \%$ from those of the free $\mathrm{Eu}^{3+}$ ion, and vary significantly within the Keggin family. Additionally, the limited absorption bandwidth of the probe may have resulted in attenuated intensities of the outer sidebands and therefore in apparent smaller observed anisotropy.

The deviations between the experimental and the calculated $\Delta \delta$ for the P2 sites in the WellsDawson compounds are generally greater than those for P1 sites. We attribute this to the weaker electron-nuclear interaction for this phosphorus atom, which is of the similar order of magnitude as the ${ }^{31} \mathrm{P}$ chemical shielding anisotropy. The experimentally measured anisotropy contains comparable contributions of the electron-nuclear dipolar and chemical shielding anisotropies, giving rise to the larger discrepancies between experiment and calculations. Quantum mechanical calculations of the CSA tensor could reveal the contribution of this term to the overall anisotropy. However, these calculations at present are challenging in rare earth polyoxoanions due to their size and the presence of a large number of heavy atoms.

The experimental and calculated asymmetry parameters are not in any agreement, with the experimental values being generally much higher than the predictions (illustrated in Figure 10b). We have observed similar behavior in the Eu-substituted Keggin and Wells-Dawson solids. 33,34 These findings indicate that the experimentally measured tensors contain a contribution from the chemical shift anisotropy term, and even though its magnitude is relatively small, and the error introduced in the measurement of the electron-nuclear dipolar tensor anisotropy $\Delta \delta$ is also small, its influence on the asymmetry parameter may be more significant, especially in the cases where the asymmetry parameters corresponding to the CSA and the electron-nuclear dipolar tensor are very different (e.g., axial CSA and rhombic electronnuclear dipolar tensor or vice versa). Whether or not the experimental asymmetry parameters may thus be a useful (if quantitative) probe of the contribution of the CSA term to the overall combined experimental electron-nuclear/chemical-shielding anisotropy tensor remains to be explored in the future. 
As already discussed, the above calculations were performed by including the paramagnetic sites within $100 \AA$ of the phosphorus atom. However, this kind of analysis relies on the X-ray coordinates and would not be feasible in the non-crystalline solids. In order to assess the utility of the electron-nuclear dipolar interaction as a structural probe of paramagnetic environments in the absence of long-range order, we calculated the anticipated P-Ln distances for the WellsDawson compounds II-V assuming that the electron-nuclear dipolar interaction originates from a single P-Ln pair and using equation 3 without the a priori knowledge of the atomic coordinates. According to the results compiled in Table 4, the effective NMR-derived distances are systematically longer than the $\mathrm{X}$-ray distances between the phosphorus atom and its closest neighbor. This is expected due to the contributions of several Ln sites to the overall electronnuclear dipolar interaction. In the Wells-Dawson isomers under study, the two or three Ln atoms that are within $14 \AA$ of the $\mathrm{P}$ site dictate the magnitude of the dipolar tensor. The relative geometries of $\mathrm{P}$ and Ln sites in these solids are such that the magnitude of the combined electron-nuclear dipolar interaction is somewhat reduced compared to the electron-nuclear dipolar interaction that would originate from a single Ln center closest to the P site of interest. Larger deviations between the NMR and the X-ray distances were observed for the P2 site, which is not surprising because the shortest P2-Ln distance is between 6.03 and $8.09 \AA$ in the $\alpha 1$ - and $\alpha 2$-isomers, respectively, and therefore the contributions from the chemical shielding anisotropy term and from the dipolar interactions the other lanthanide neighbors become large. The deviations between NMR and X-ray distances observed for the P2 site in the 2:2 Ln: $\alpha_{2}$ $\mathrm{P}_{2} \mathrm{~W}_{17} \mathrm{O}_{61}$ complexes may also be derived from the differences in the proximity of the $\mathrm{Ln}$ ion in the adjacent polyoxometalate of the "cap to cap" or "cap to belt" dimers.

Based on the above results we conclude that the distance estimates from the observed electronnuclear dipolar interaction assuming a single P-Ln pair are only useful for assignments of the individual phosphorus sites (P1 vs. P2). However, the present studies were conducted on crystalline solids containing extended networks of neighboring anions. We anticipate that in systems where the individual polyoxoanions are isolated (e.g., in films) the single pair approximation might yield accurate distances.

\section{Rare Earth Substitutions as NMR Structural Probes in Paramagnetic Polyoxoanionic Solids}

The results discussed above indicate that paramagnetic lanthanides are generally useful as structural probes in polyoxoanionic solids, and that ${ }^{31} \mathrm{P}$ solid-state NMR spectroscopy presents a quick non-destructive probe of the local geometry of the lanthanide-substituted WellsDawson and Keggin solids. As illustrated in Table 2, the anisotropy and asymmetry parameters of the electron-nuclear dipolar coupling tensors allow to determine quickly and unambiguously the salient structural features of the polyoxoanionic solids: 1) the nature of the polyoxoanion (i.e., Keggin vs. Wells-Dawson); and 2) positional isomerism and the anion stoichiometry ( $\alpha 1$ 1:2 - vs. $\alpha 22: 2$ - isomers). This approach is expected to be an important addition to the current methods for characterization of polyoxometalates because not always can one predict the outcome of the synthesis of a specific polyoxometalate solid and/or of the identity of the POM once incorporated into a solid material, such as a mesoporous solid or hybrid organic/ inorganic material. These materials are usually noncrystalline and lack long-range order, and therefore structural information is very hard to gain.

One of the goals of our study was to assess the utility of different trivalent rare earth ions as NMR probes of local environments in paramagnetic polyxoanionic solids. Our results indicate that as expected, the electron-nuclear dipolar anisotropies within a particular family of structurally homologous polyoxometalates are determined by the effective electronic magnetic moments of the rare earth atom (which vary from 2.54 to $10.6 \mu \mathrm{B}$ across the series). As discussed above, ${ }^{31} \mathrm{P}$ NMR spectra were readily detectable for Wells-Dawson solids under investigation containing lanthanides with both moderate (e.g., $\mathrm{Ce}, \mathrm{Nd}, \mathrm{Pr}, \mathrm{Eu}$ ) and large 
magnetic moments (e.g., Er), and the experimental and predicted NMR parameters were in good agreement. A potential advantage of employing lanthanides with large magnetic moments in studying non-crystalline polyoxometalates is that presence of more distant paramagnetic centers can be detected. Therefore, it will be of interest to address in the future the SSNMR behavior of Gd-, Dy- and Tb-Wells-Dawson solids.

For tetrameric Keggin polyoxometalates substituted with lanthanides possessing moderate magnetic moments (Pr, Nd, Eu) the ${ }^{31} \mathrm{P}$ MAS spectra were readily detectable, and the experimental parameters were generally in good agreement with the predicted electron-nuclear dipolar anisotropies. We therefore conclude that these lanthanides could be generally utilized as structural probes potentially useful for addressing paramagnetic environments in polyoxometalate solids lacking long-range order.

As discussed above, the ${ }^{31} \mathrm{P}$ NMR signals could not be detected in Gd-, Dy- and Tb-substituted tetrameric Keggin polyoxometalates XI-XIII. Surprisingly, at the same time ${ }^{31}$ P MAS NMR spectra were easily detectable for the Er-substituted solid, despite the large magnetic moment of $\mathrm{Er}^{3+}(9.6 \mu \mathrm{B})$. However, the individual spinning sidebands of Er-containing $\mathbf{I X}$ were broad, and the isotropic chemical shifts of the non-equivalent phosphorus sites overlapped. Significant deviations were observed between the experimental and predicted electron-nuclear dipolar anisotropies. These results suggest that rare earth ions with large magnetic moments may not be effective as paramagnetic structural probes in tetrameric Keggin solids. We speculate that the crystal packing in the tetrameric Er-, Gd-, Dy-, and Tb-substituted Keggin complexes is different enough, so that broadening of the lines beyond detection in Gd-, Dy-, and Tbderivatives might be the result of intermolecular interactions.

\section{Outlook and Applications to Other Systems}

Paramagnetic lanthanides can generally be employed as structural probes via ${ }^{31}$ P MAS NMR spectroscopy in inorganic solids other than polyoxometalates. As discussed above and summarized in Table 1, the effective magnetic moments across the lanthanide series span a broad range from 2.54 to $10.6 \mu \mathrm{B}$. Therefore, the strength of the electron-nuclear interaction for a particular phosphorus-lanthanide distance will vary widely depending on the nature of the lanthanide atom. Alternatively stated, the longest distance between the phosphorus atom and the paramagnetic lanthanide center that can be detectable by ${ }^{31} \mathrm{P}$ solid-state NMR, will be dictated by the lanthanide's effective magnetic moment. Therefore, the choice of a particular lanthanide as a structural probe can be tailored to the anticipated ${ }^{31} \mathrm{P}$-lanthanide distance in the material of interest. To illustrate this, in Table 1 the distances at which the electron-nuclear dipolar interaction is $10 \mathrm{ppm}$ (the smallest-magnitude coupling that can be reliably determined at $9.4 \mathrm{~T}$, under the condition that the ${ }^{31} \mathrm{P}$ chemical shift anisotropy is considerably smaller than $10 \mathrm{ppm}$ ) are summarized for different lanthanides. These represent the longest P-lanthanide distances at which the presence of the paramagnetic rare earth center can be detected assuming a single P-lanthanide pair. We note that the longest distance that can be measured using this approach will be dictated by the ${ }^{31} \mathrm{P}$ chemical shift anisotropy: the electron-nuclear dipolar interaction has to exceed the chemical shift anisotropy. Assuming that ${ }^{31} \mathrm{P} \mathrm{CSA}$ is smaller than 10 ppm, the longest distances that can be measured range between $9.6 \AA$ (for Ce possessing the smallest magnetic moment) and $25 \AA$ (for Dy and Ho whose magnetic moments are the largest across the series). That ${ }^{31} \mathrm{P}$-lanthanide electron-nuclear dipolar coupling is readily detectable at such long distances can be conveniently exploited for structural studies of solids with dilute paramagnetic labels, for instance of hybrid organic-inorganic lanthanide-containing materials. Moreover, for the same kind of solid, the most fruitful strategy could involve preparation of several samples containing different lanthanides as it will allow for probing local structure for different distance cutoffs. 


\section{Conclusions}

In conclusion, this work demonstrates that paramagnetic lanthanides with different magnetic moments are generally useful as structural probes in polyoxoanionic solids. ${ }^{31} \mathrm{P}$ MAS NMR spinning sideband envelopes in the rare-earth substituted paramagnetic polyoxotungstates from the Wells-Dawson and Keggin families are dominated by the anisotropic electron-nuclear dipolar interaction. The anisotropy of the electron-nuclear dipolar tensor is determined by the effective magnetic moment of the rare earth atom, and by the local geometry of the paramagnetic centers. The magnitude of the electron-nuclear dipolar interaction in polyoxometalates substituted with the same rare earth atom reports on the nature of the polyoxoanion, on the positional isomerism, and on the ion stoichiometry.

The results indicate that the choice of a specific rare earth atom as the structural reporter can be tuned to the distance range to be probed in the solid. For Wells-Dawson solids, lanthanides with both moderate and large magnetic moments can used, while in tetrameric Keggin compounds lanthanides with moderate magnetic moments should be employed. This approach is expected to be broadly applicable to paramagnetic solids other than polyoxometalates and is anticipated to be especially useful in inorganic materials lacking long-range order.

\section{Supplementary Material}

Refer to Web version on PubMed Central for supplementary material.

\section{References}

(1). Bekiari V, Lianos P. Adv. Mater 1998;10:1455-1458.

(2). Buonocore GE, Li H, Marciniak B. Coord. Chem. Rev 1990;99:55-87.

(3). Howell RC, Perez FG, Jain S, Horrocks WD, Rheingold AL, Francesconi LC. Angew Chem Int Edit 2001;40:4031.

(4). Luo QH, Howell RC, Bartis J, Dankova M, Horrocks WD, Rheingold AL, Francesconi LC. Inorg. Chem 2002;41:6112-6117. [PubMed: 12425640]

(5). Luo QH, Howell RC, Dankova M, Bartis J, Williams CW, Horrocks WD, Young VG, Rheingold AL, Francesconi LC, Antonio MR. Inorg. Chem 2001;40:1894-1901. [PubMed: 11312747]

(6). Zhang C, Bensaid L, McGregor D, Fang XF, Howell RC, Burton-Pye B, Luo QH, Todaro L, Francesconi LC. J. Clust. Sci 2006;17:389-425.

(7). Zhang C, Howell RC, Luo QH, Fieselmann HL, Todaro LJ, Francesconi LC. Inorg. Chem 2005;44:3569-3578. [PubMed: 15877440]

(8). Bartis J, Dankova M, Lessmann JJ, Luo QH, Horrocks WD, Francesconi LC. Inorg. Chem 1999;38:1042-1053. [PubMed: 11670884]

(9). Zhang H, Lin X, Yan Y, Wu L. Chem. Comm 2006;44:4575-4577. [PubMed: 17082847]

(10). Wang Z, Wang J, Zhang HJ. Mater. Chem. Phys 2004;87:44-48.

(11). Wang J, Wang Z, Wang HS, Liu FY, Fu LH, Zhang HJ. J. Alloys Compd 2004;376:68-72.

(12). Xu L, Zhang H, Wang E, Wu A, Li Z. Mater. Lett 2002;54:452-457.

(13). Xu L, Zhang H, Wang E, Wu A, Li Z. Mater. Chem. Phys 2003;77:484-488.

(14). Wang J, Wang HS, Fu LS, Liu FY, Zhang HJ. Thin Solid Films 2002;414:256-261.

(15). Sousa FL, Pillinger M, Sa Ferreira RA, Granadeiro CM, Cavaleiro AMV, Rocha J, Carlos LD, Trindade T, Nogueira HIS. Eur. J. Inorg. Chem 2006;4:726-734.

(16). Ma HY, Peng J, Han ZG, Feng YH, Wang E. Thin Solid Films 2004;446:161-166.

(17). Lu X, Liu X, Wang L, Zhang W, Wang C. Nanotech 2006;17:3048-3053.

(18). Hoa DTM, Kim HS, Lee B-J, Kwon Y-S. Mol. Cryst. Liq. Cryst 2006;444:113-120.

(19). Niu J, Zhao J, Wang J, Ma P. J. Mol. Struct 2004;699:85-92.

(20). Wang J-P, Han Q-X, Niu J-Y. Transition Met. Chem 2004;29:170-174. 
(21). Zhang C, Howell RC, Scotland KB, Perez FG, Todaro L, Francesconi LC. Inorg. Chem 2004;43:7691-7701. [PubMed: 15554634]

(22). Zhang C, Howell RC, McGregor D, Bensaid L, Rahyab S, Nayshtut M, Lekperic S, Francesconi LC. C. R. Chim 2005:235-243.

(23). Mialane P, Lisnard L, Mallard A, Marrot J, Antic-Fidancev E, Aschehoug P, Vivien D, Secheresse F. Inorg. Chem 2003;42:2102-2108. [PubMed: 12639147]

(24). Naruke H, Yamase T, Kaneko M. Bull. Chem. Soc. Jpn 1999;72:1775-1779.

(25). Gao GG, Xu L, Wang WJ, An WJ, Qiu YF. J. Mater. Chem 2004;14:2024-2029.

(26). Day VW, Klemperer WG. Science 1985;228:533-541. [PubMed: 17736064]

(27). Day, VW.; Klemperer, WG.; Schwartz, C.; Wang, R-C. Surface Organometallic Chemistry: Molecular Approaches to Surface Catalysis. Kluwer Academic Publishers; New York: 1988. p. 173

(28). Fang X, Hill CL. Angew. Chem. Int. Ed 2007;46:3877-3880.

(29). Leclerc-Laronze N,M, Haouas M, Marrot J, Taulelle F, Herve G. Angew. Chem. Int. Ed 2006;45:139-142.

(30). Reinoso S, Dickman MH, Reicke M, Kortz U. Inorg. Chem 2006;45:9014-9019. [PubMed: 17054362]

(31). Sadakane M, Dickman MH, Pope MT. Angew. Chem. Int. Ed 2000;39:2914-2916.

(32). Zimmermann M, Belai N, Butcher RJ, Pope MT, Chubarova EV, Dickman MH, Kortz U. Inorg. Chem 2007;46:1737-1740. [PubMed: 17295478]

(33). Huang W, Schopfer M, Zhang C, Howell RC, Gee BA, Francesconi LC, Polenova T. J. Phys. Chem. B 2006;110:12340-12350. [PubMed: 16800557]

(34). Huang, W. e.; Francesconi, LC.; Polenova, T. Inorg. Chem. 2007in press

(35). Brough AR, Grey CP, Dobson CM. J. Chem. Soc. Chem. Comm 1992:742-743.

(36). Brough AR, Grey CP, Dobson CM. J. Am. Chem. Soc 1993;115:7318-7327.

(37). Lee H, Polenova T, Beer RH, McDermott AE. J. Am. Chem. Soc 1999;121:6884-6894.

(38). Lee YJ, Grey CP. J. Phys. Chem. B 2002;106:3576-3582.

(39). Lin TH, Dinatale JA, Vold RR. J. Am. Chem. Soc 1994;116:2133-2134.

(40). Liu K, Ryan D, Nakanishi K, Mcdermott A. J. Am. Chem. Soc 1995;117:6897-6906.

(41). Nayeem A, Yesinowski JP. J. Chem. Phys 1988;89:4600-4608.

(42). Tucker MC, Doeff MM, Richardson TJ, Finones R, Reimer JA, Cairns EJ. Electrochem. Solid St 2002;5:A95-A98.

(43). Woehler SE, Wittebort RJ, Oh SM, Hendrickson DN, Inniss D, Strouse CE. J. Am. Chem. Soc 1986;108:2938-2946.

(44). Sadakane M, Ostuni A, Pope MT. J. Chem. Soc. Dalton 2002:63-67.

(45). Cobas, J.; Cruces, J.; Sardina, FJ. Departmento de Quimica Organica, Facultat de Quimica. Universidad de Santiago de Compostela; Spain: 2000.

(46). Bak M, Rasmussen JT, Nielsen NC. J. Magn. Reson 2000;147:296-330. [PubMed: 11097821]

(47). Herzfeld J, Berger AE. J. Chem. Phys 1980;73:6021-6030.

(48). Eichele, K.; Wasylishen, RE. 2001. 1.4.4 ed.

(49). Rossat-Mignod, J. Systematics and the Properties of the Lanthanides. Sinha, SP., editor. 1. D. Reidel Pub. Co.; Boston: 1983. p. 258

(50). Abragam, A.; Bleaney, B. Electron Paramagnetic Resonance of Transition Ions. 1 ed.. 1. Clarendon Press; Oxford: 1970. 


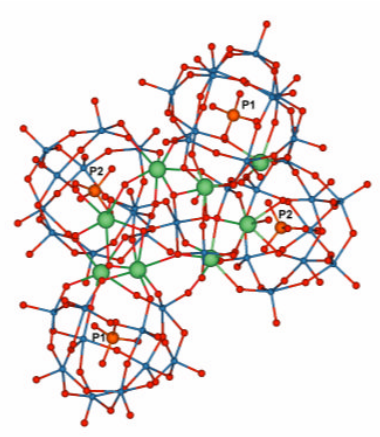

a)

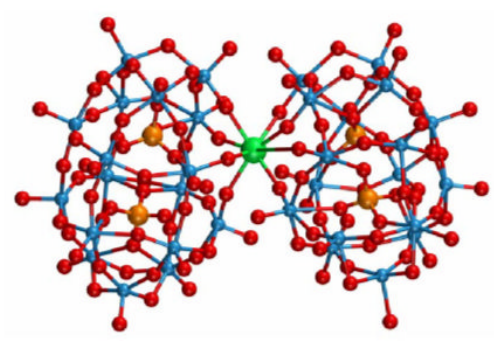

b)

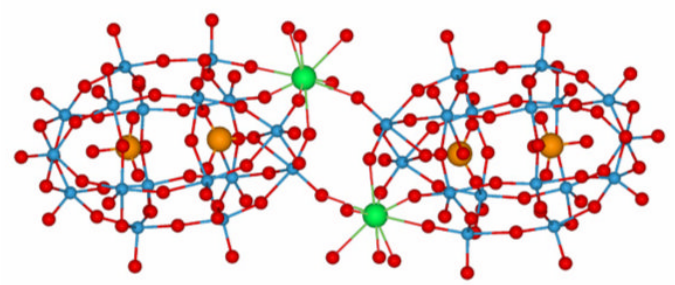

c)

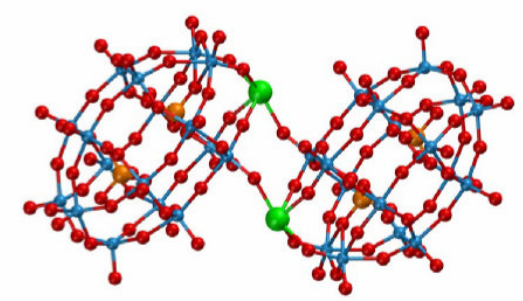

d)

Figure 1.

The schematic representations of rare-earth substituted polyoxotungstate anions: (a) tetrameric Keggin compounds, (b) $\alpha_{1}$-Wells-Dawson isomers forming 1:2 $\mathrm{Ln}$ :anion complexes, (c) and (d) $\alpha_{2}$-Wells-Dawson isomers forming 2:2 Ln:anion complexes. The dimeric POM units for the early lanthanides ( $\mathrm{La}, \mathrm{Ce}, \mathrm{Pr}$ ) exhibit cap to cap connection shown in (c). The later lanthanides (Nd, Lu) exhibit cap to belt connection shown in (d). The molecules are depicted in a ball-and-stick representation. In the anion, the tungsten atoms are shown in blue, the central $\mathrm{P}$ atom(s) is (are) shown in orange. The rare earth atom(s) is (are) shown in green. 


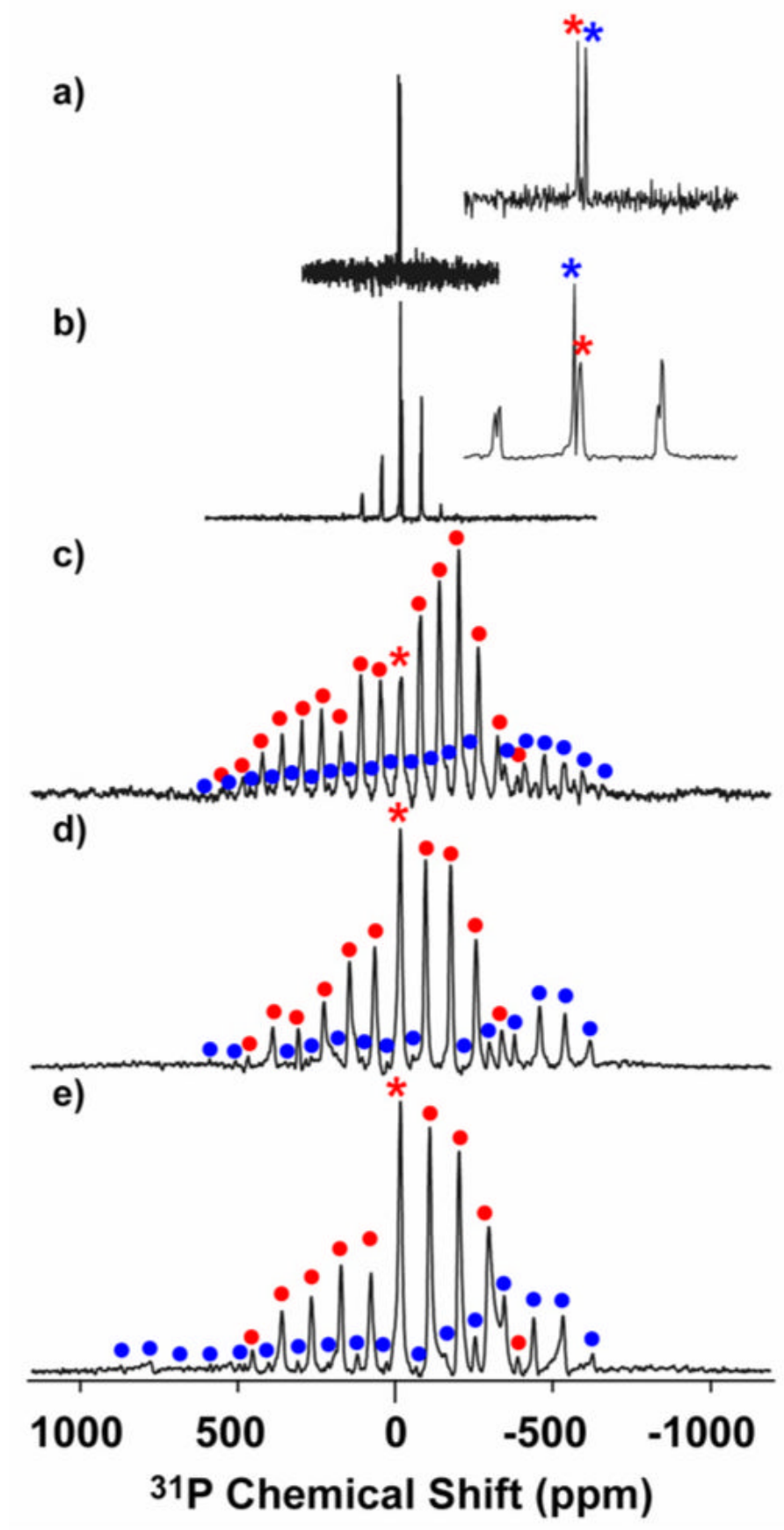

Figure 2.

${ }^{31} \mathrm{P}$ MAS NMR spectra of lanthanide substituted Wells-Dawson compounds a) $\mathrm{K}_{14}\left(\mathrm{H}_{3} \mathrm{O}\right)_{3}[\mathrm{La}$ $\left.\left(\alpha_{1}-\mathrm{P}_{2} \mathrm{~W}_{17} \mathrm{O}_{61}\right)_{2}\right] \cdot 4 \mathrm{KCl} \cdot 64 \mathrm{H}_{2} \mathrm{O}(\mathbf{I})$, b) $\mathrm{K}_{14}\left(\mathrm{H}_{3} \mathrm{O}\right)_{3}\left[\mathrm{Nd}\left(\alpha_{1}-\mathrm{P}_{2} \mathrm{~W}_{17} \mathrm{O}_{61}\right)_{2}\right] \cdot 4 \mathrm{KCl} \cdot 64 \mathrm{H}_{2} \mathrm{O}$ (II), c)e) $\mathrm{K}_{14}\left(\mathrm{H}_{3} \mathrm{O}\right)_{3}\left[\operatorname{Er}\left(\alpha_{1}-\mathrm{P}_{2} \mathrm{~W}_{17} \mathrm{O}_{61}\right)_{2}\right] \cdot 4 \mathrm{KCl} \cdot 64 \mathrm{H}_{2} \mathrm{O}$ (III). The spectra a)-c) were acquired at a spinning frequency of $10 \mathrm{kHz}$; spectrum d)-at $13 \mathrm{kHz}$, e)-at $15 \mathrm{kHz}$. The isotropic chemical shifts are compiled in Table 2 (referenced to $85 \% \mathrm{H}_{3} \mathrm{PO}_{4}$ ). In c), d), and e) the spinning sidebands corresponding to the $\mathrm{P} 1$ site are shown with blue markers, to $\mathrm{P} 2$-with red markers. The isotropic peaks in all spectra are marked with red asterisks (P1) and blue asterisks (P2). 


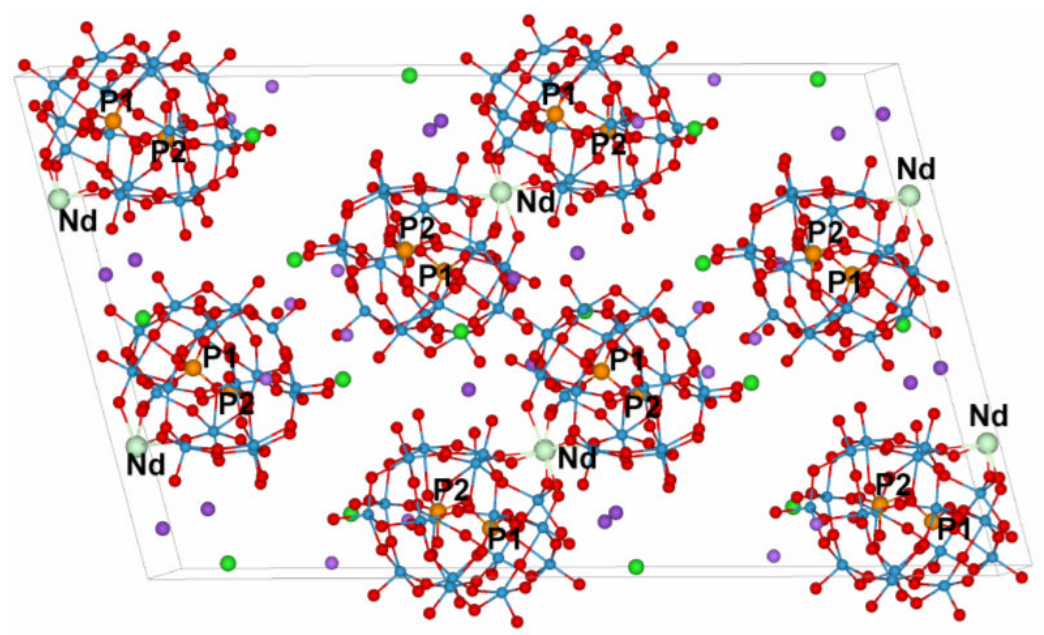

Figure 3.

Unit cell of $\mathrm{K}_{14}\left(\mathrm{H}_{3} \mathrm{O}\right)_{3}\left[\mathrm{Nd}\left(\alpha_{1}-\mathrm{P}_{2} \mathrm{~W}_{17} \mathrm{O}_{61}\right)_{2}\right] \cdot 4 \mathrm{KCl} \cdot 64 \mathrm{H}_{2} \mathrm{O}$ (II), view down the crystallographic $a$ axis. The molecule is depicted in ball-and-stick representation. Counter cations and uncoordinated $\mathrm{H}_{2} \mathrm{O}$ molecules have been removed for clarity. Legend: W, blue; $\mathrm{O}$, red; $\mathrm{Nd}$, pale gray; $\mathrm{P}$, orange. 


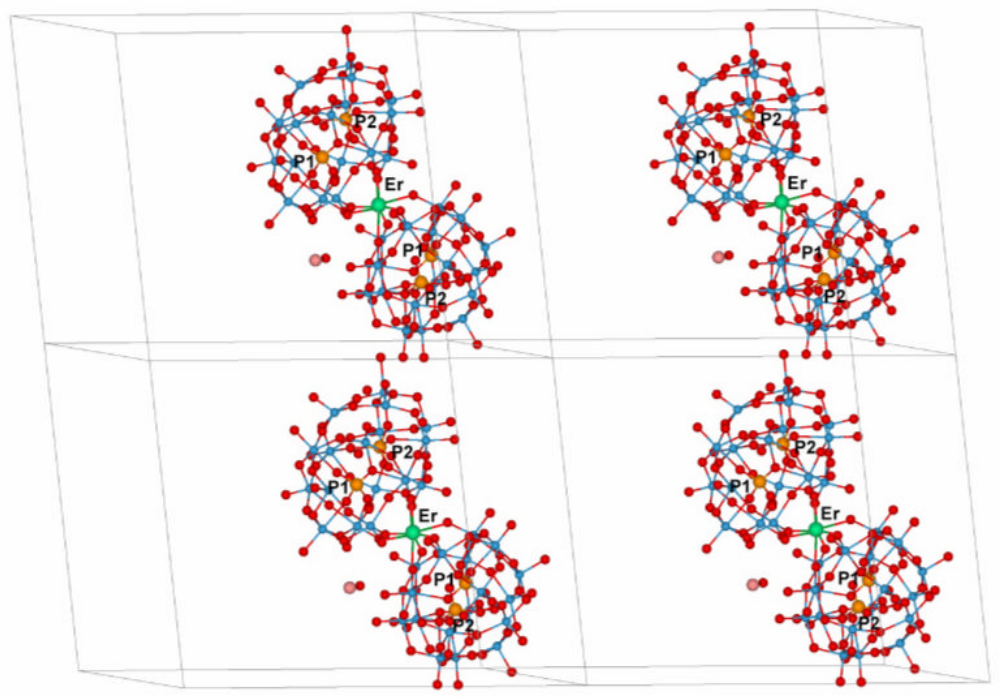

Figure 4.

Unit cell of $\mathrm{K}_{14}\left(\mathrm{H}_{3} \mathrm{O}\right)_{3}\left[\mathrm{Er}\left(\alpha_{1}-\mathrm{P}_{2} \mathrm{~W}_{17} \mathrm{O}_{61}\right)_{2}\right] \cdot 4 \mathrm{KCl} \cdot 64 \mathrm{H}_{2} \mathrm{O}$ (III), view down the crystallographic $a$ axis. The molecule is depicted in ball-and-stick representation. Counter cations and uncoordinated $\mathrm{H}_{2} \mathrm{O}$ molecules have been removed for clarity. Legend: $\mathrm{W}$, blue; $\mathrm{O}$, red; Er, green; $\mathrm{P}$, orange. 


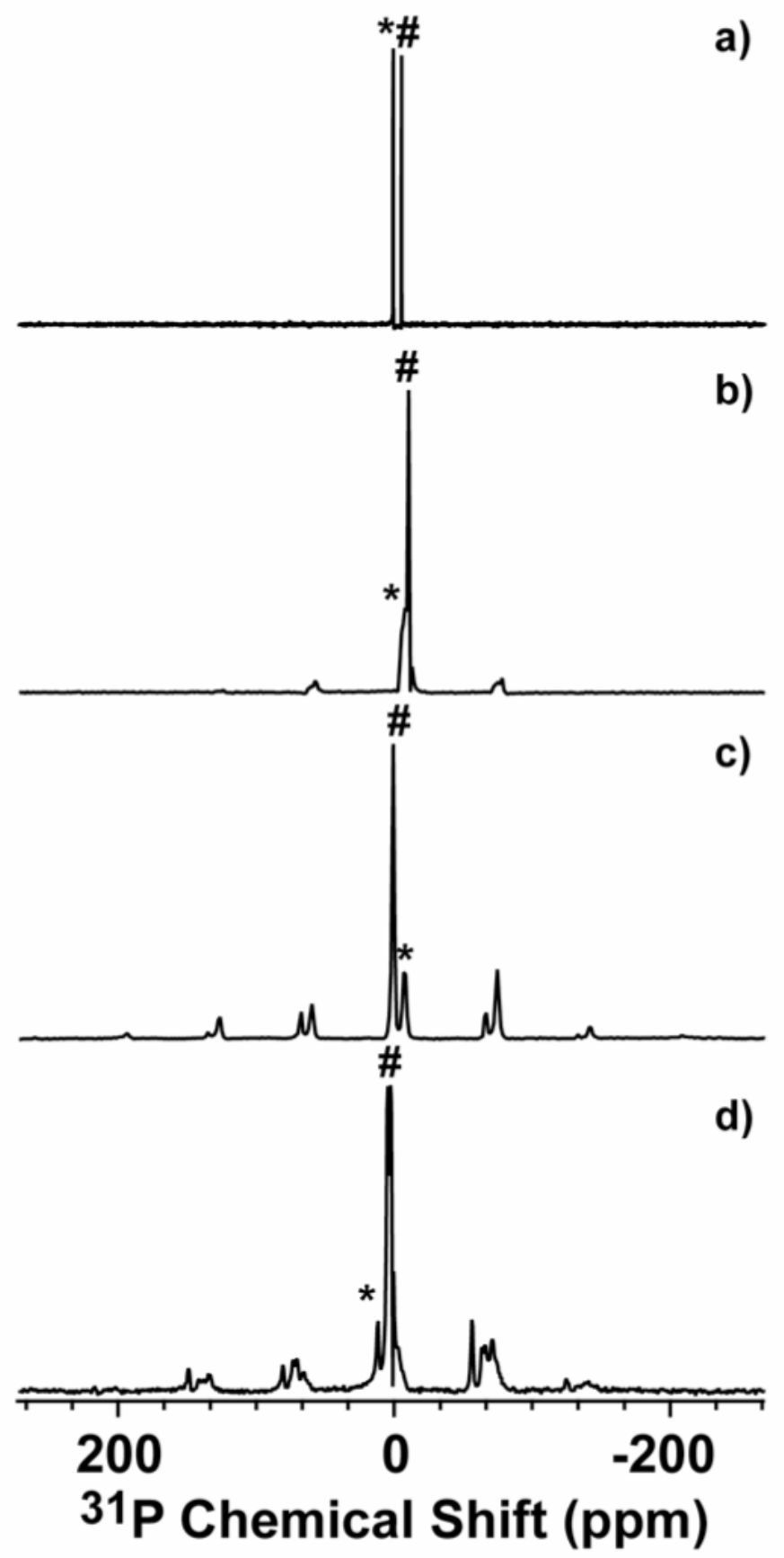

Figure 5.

${ }^{31} \mathrm{P}$ MAS NMR spectra of lanthanide substituted Wells-Dawson compounds a) $\mathrm{K}_{13}\left(\mathrm{H}_{3} \mathrm{O}\right)$ [Lu $\left.\left(\mathrm{H}_{2} \mathrm{O}\right)_{3}\left(\alpha_{2}-\mathrm{P}_{2} \mathrm{~W}_{17} \mathrm{O}_{61}\right)\right]_{2} \cdot 2 \mathrm{KCl} \cdot \mathrm{nH}_{2} \mathrm{O}$ (VII), b) $\mathrm{K}_{13}\left(\mathrm{H}_{3} \mathrm{O}\right)\left[\mathrm{Ce}\left(\mathrm{H}_{2} \mathrm{O}\right)_{4}\left(\alpha_{2}-\right.\right.$ $\left.\left.\left.\mathrm{P}_{2} \mathrm{~W}_{17} \mathrm{O}_{61}\right)\right]_{2} \cdot 2 \mathrm{KCl} \cdot \mathrm{nH}_{2} \mathrm{O}(\mathbf{I V}), \mathrm{c}\right) \mathrm{K}_{13}\left(\mathrm{H}_{3} \mathrm{O}\right)\left[\mathrm{Nd}\left(\mathrm{H}_{2} \mathrm{O}\right)_{3}\left(\alpha_{2}-\mathrm{P}_{2} \mathrm{~W}_{17} \mathrm{O}_{61}\right)\right]_{2} \cdot 2 \mathrm{KCl} \cdot \mathrm{nH}_{2} \mathrm{O}(\mathbf{V})$, and d) $\mathrm{K}_{13}\left(\mathrm{H}_{3} \mathrm{O}\right)\left[\mathrm{Pr}\left(\mathrm{H}_{2} \mathrm{O}\right)_{4}\left(\alpha_{2}-\mathrm{P}_{2} \mathrm{~W}_{17} \mathrm{O}_{61}\right)\right]_{2} \cdot 2 \mathrm{KCl} \cdot \mathrm{nH}_{2} \mathrm{O}(\mathbf{V I})$ at a spinning frequency of 5 $\mathrm{kHz}$. The center bands are marked with an asterisk (P1) and a pound (P2). The isotropic chemical shifts are compiled in Table 2 (referenced to $85 \% \mathrm{H}_{3} \mathrm{PO}_{4}$ ). 


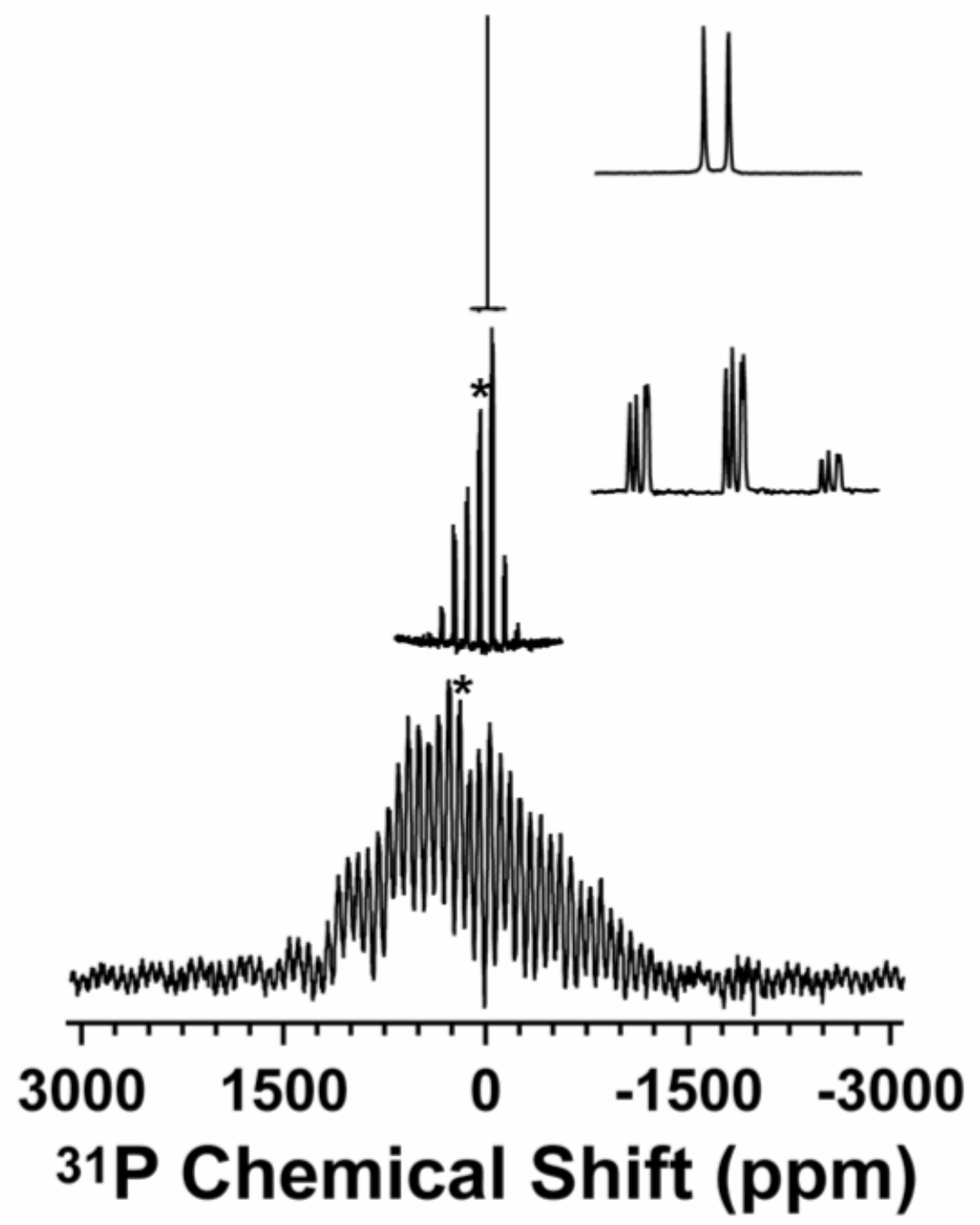

Figure 6.

Experimental ${ }^{31} \mathrm{P}$ MAS NMR spectra of lanthanide substituted tetrameric Keggin oxotungstates: a) $\mathrm{Na}_{8} \mathrm{~K}_{5}\left(\mathrm{H}_{3} \mathrm{O}\right)_{19} \mathrm{Cl}_{10}\left[\left(\mathrm{Y}_{2} \mathrm{PW}_{10} \mathrm{O}_{38}\right)_{4} \mathrm{~W}_{3} \mathrm{O}_{8}\left(\mathrm{H}_{2} \mathrm{O}\right)_{2}(\mathrm{OH})_{4}\right] \cdot\left(\mathrm{CH}_{3} \mathrm{OH}\right) \cdot 32 \mathrm{H}_{2} \mathrm{O}$ (VIII), b) $\left(\mathrm{NH}_{4}\right)_{22}\left[\left(\mathrm{Eu}_{2} \mathrm{PW}_{10} \mathrm{O}_{38}\right)_{4}\left(\mathrm{~W}_{3} \mathrm{O}_{8}\left(\mathrm{H}_{2} \mathrm{O}\right)_{2}(\mathrm{OH})_{4}\right)\right] \cdot 44 \mathrm{H}_{2} \mathrm{O}(\mathbf{X})$, and c) $\left.\mathrm{Na}_{8} \mathrm{~K}_{5}\left(\mathrm{H}_{3} \mathrm{O}\right)_{19} \mathrm{Cl}_{10}\left[\left(\mathrm{Er}_{2} \mathrm{PW}_{10} \mathrm{O}_{38}\right)_{4} \mathrm{~W}_{3} \mathrm{O}_{8}\left(\mathrm{H}_{2} \mathrm{O}\right)_{2}(\mathrm{OH})_{4}\right)\right] \cdot\left(\mathrm{CH}_{3} \mathrm{OH}\right) \cdot 32 \mathrm{H}_{2} \mathrm{O}(\mathbf{I X})$. The spectra of compound VIII were collected at spinning frequency of $10 \mathrm{kHz}$, the other spectra were collected at $15 \mathrm{kHz}$. The insets in a) and b) depict the centerbands of VIII and $\mathbf{X}$, which are marked with an asterisk (P1) and a pound (P2), respectively. The isotropic chemical shifts are compiled in Table 2 (referenced to $85 \% \mathrm{H}_{3} \mathrm{PO}_{4}$ ). 


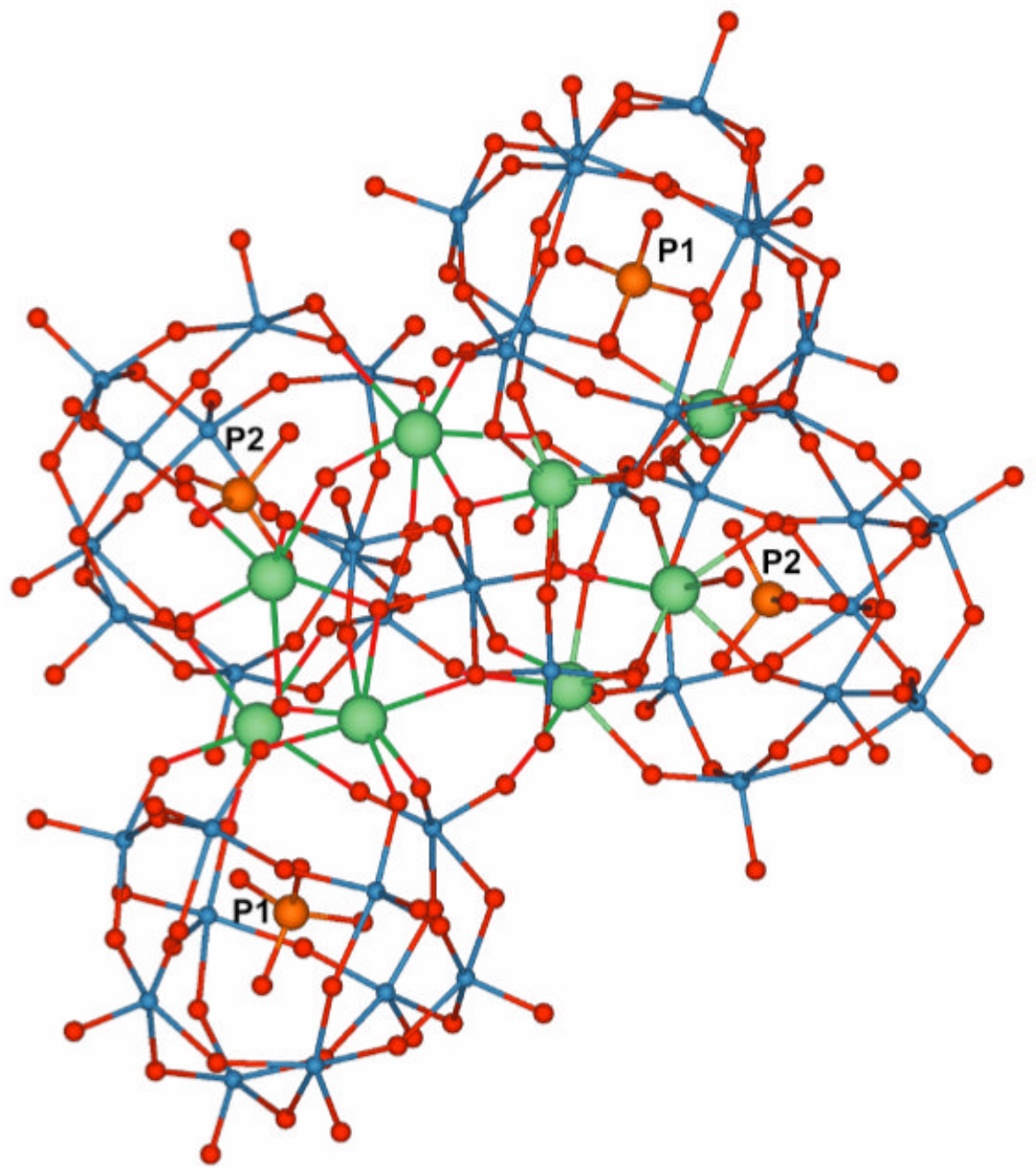

Figure 7.

Coordination environment of the tetrameric Keggin compound $\left.\mathrm{Na}_{8} \mathrm{~K}_{5}\left(\mathrm{H}_{3} \mathrm{O}\right)_{19} \mathrm{Cl}_{10}\left[\left(\mathrm{Er}_{2} \mathrm{PW}_{10} \mathrm{O}_{38}\right)_{4} \mathrm{~W}_{3} \mathrm{O}_{8}\left(\mathrm{H}_{2} \mathrm{O}\right)_{2}(\mathrm{OH})_{4}\right)\right] \cdot\left(\mathrm{CH}_{3} \mathrm{OH}\right) \cdot 32 \mathrm{H}_{2} \mathrm{O}(\mathbf{I X})$. The molecule is depicted in ball-and-stick representation. Counter cations and uncoordinated $\mathrm{H}_{2} \mathrm{O}$ molecules have been removed for clarity. Legend: W, blue; O, red; Er, green; P, orange. The crystallographically inequivalent phosphorus sites are labeled as P1-P4 (the designation is arbitrary). 


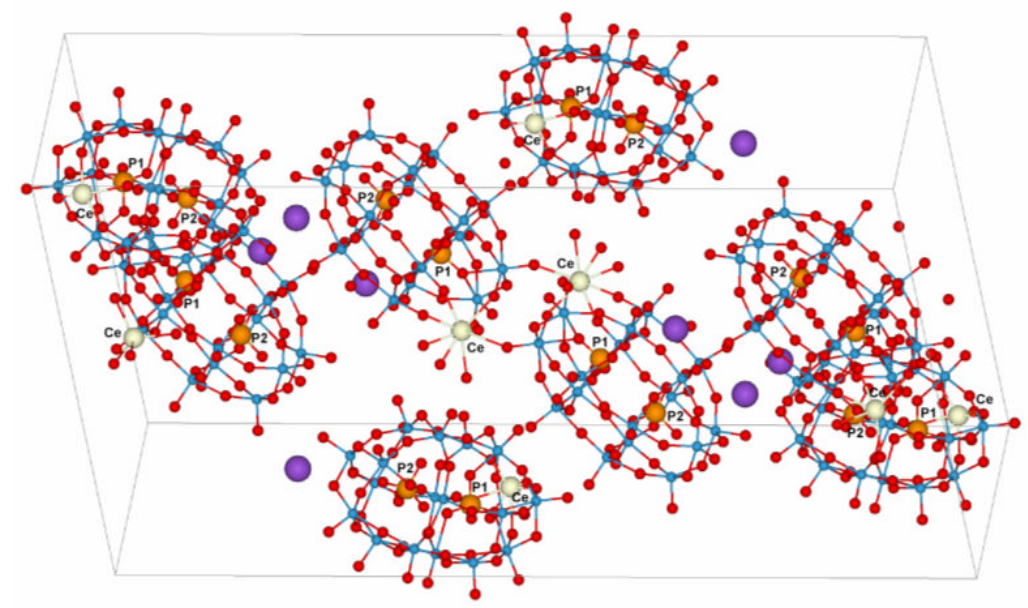

Figure 8.

Unit cell of $\mathrm{K}_{13}\left(\mathrm{H}_{3} \mathrm{O}\right)\left[\mathrm{Ce}\left(\mathrm{H}_{2} \mathrm{O}\right)_{4}\left(\alpha_{2}-\mathrm{P}_{2} \mathrm{~W}_{17} \mathrm{O}_{61}\right)\right]_{2} \cdot 2 \mathrm{KCl} \cdot \mathrm{nH}_{2} \mathrm{O}(\mathbf{I V})$, view down the crystallographic $a$ axis. The molecule is depicted in ball-and-stick representation. Countercations and uncoordinated $\mathrm{H}_{2} \mathrm{O}$ molecules have been removed for clarity. Legend: $\mathrm{W}$, blue; $\mathrm{O}$, red; Ce, pale gray; $\mathrm{P}$, orange; $\mathrm{K}$, purple. 


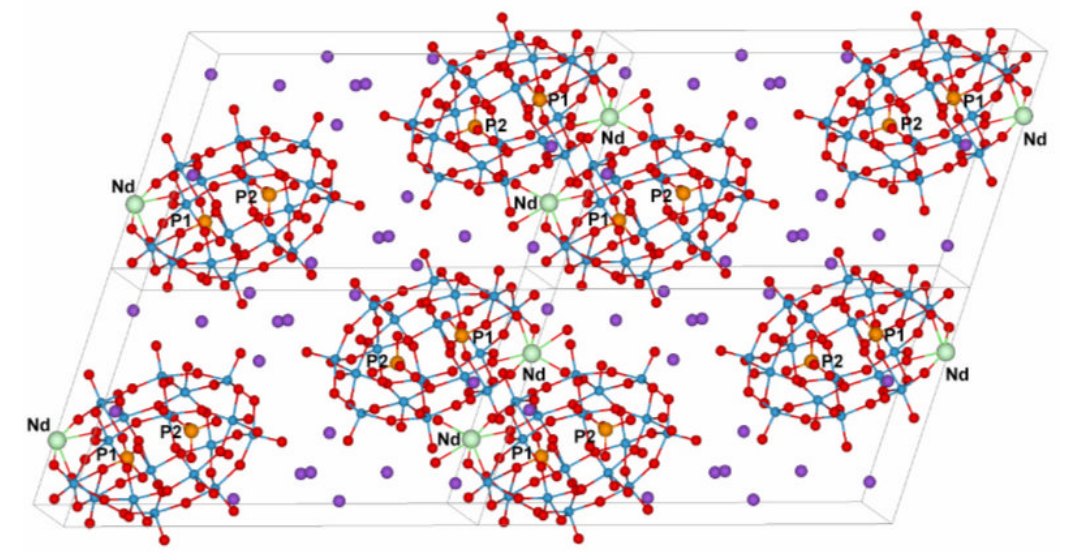

Figure 9.

Unit cell of $\mathrm{K}_{13}\left(\mathrm{H}_{3} \mathrm{O}\right)\left[\mathrm{Nd}\left(\mathrm{H}_{2} \mathrm{O}\right)_{3}\left(\alpha_{2}-\mathrm{P}_{2} \mathrm{~W}_{17} \mathrm{O}_{61}\right)\right]_{2} \cdot 2 \mathrm{KCl} \cdot \mathrm{nH}_{2} \mathrm{O}(\mathbf{V})$, view down the crystallographic $c$ axis. The molecule is depicted in ball-and-stick representation. Counter cations and uncoordinated $\mathrm{H}_{2} \mathrm{O}$ molecules have been removed for clarity. Legend: $\mathrm{W}$, blue; $\mathrm{O}$, red; $\mathrm{Nd}$, pale gray; $\mathrm{P}$, orange; $\mathrm{K}$, purple. 

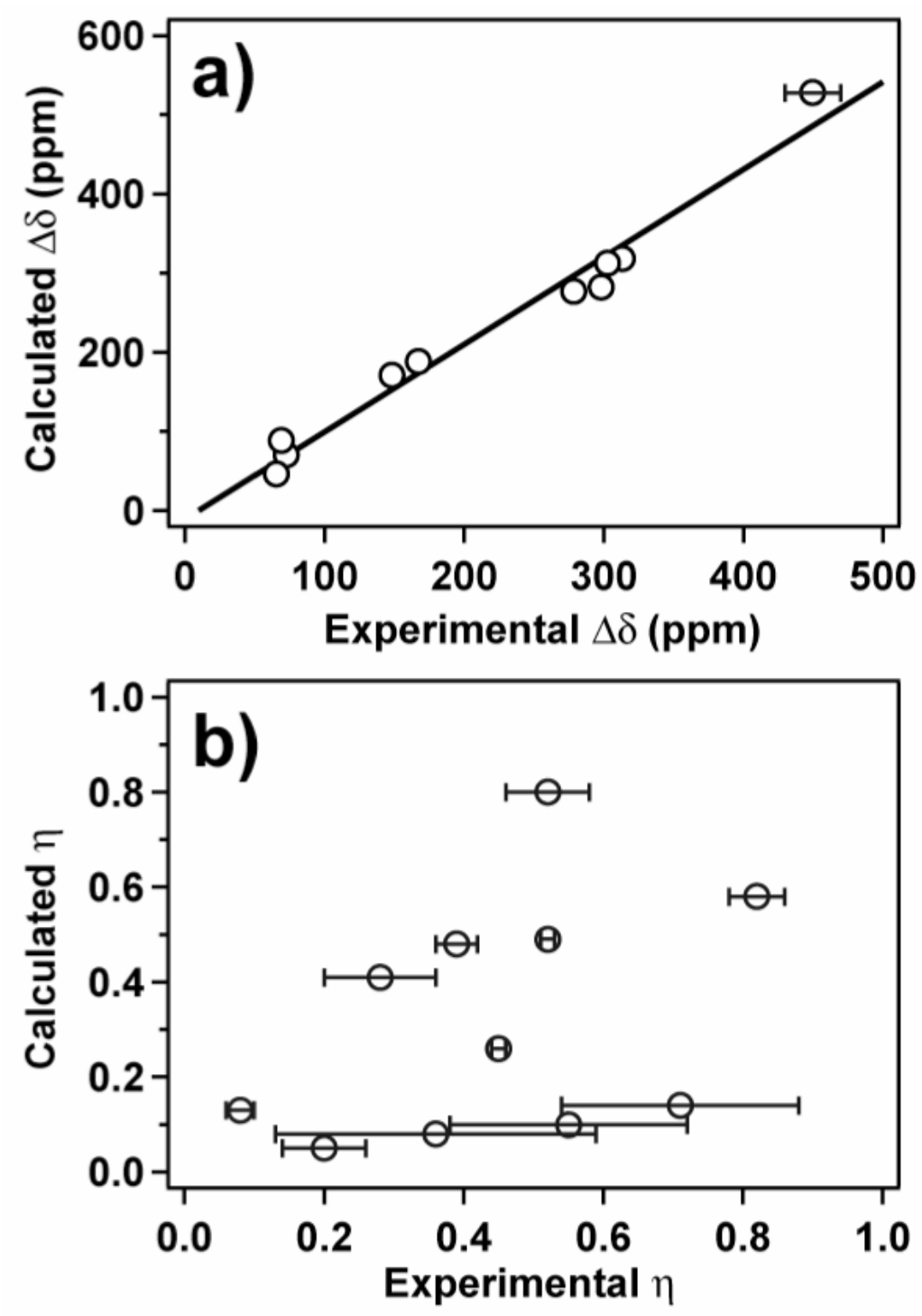

Figure 10.

Comparison of experimental and calculated anisotropic NMR observables $\Delta \delta$ (a) and $\eta$ (b) for crystallographically characterized compounds II-V and $\mathbf{X}$. For $\Delta \delta$ of P1 and P2 sites, linear correlation between the experimental and calculated parameters is: $\Delta \delta_{\text {calc }}=-10.9+1.10$ $\Delta \delta_{\text {exp }}$ (the fit shown as black line). For $\Delta \delta$ of P1 site only in II-V and $\mathbf{X}$, linear correlation between the experimental and calculated parameters is: $\Delta \delta_{\text {calc }}=-1.88+1.08 \Delta \delta_{\text {exp }}$. The error bars on the experimental values of $\Delta \delta$ (a) for all compounds except III are smaller than the marker size; the error bars for III are shown. The error bars on the experimental values of $\eta$ (b) are shown. 


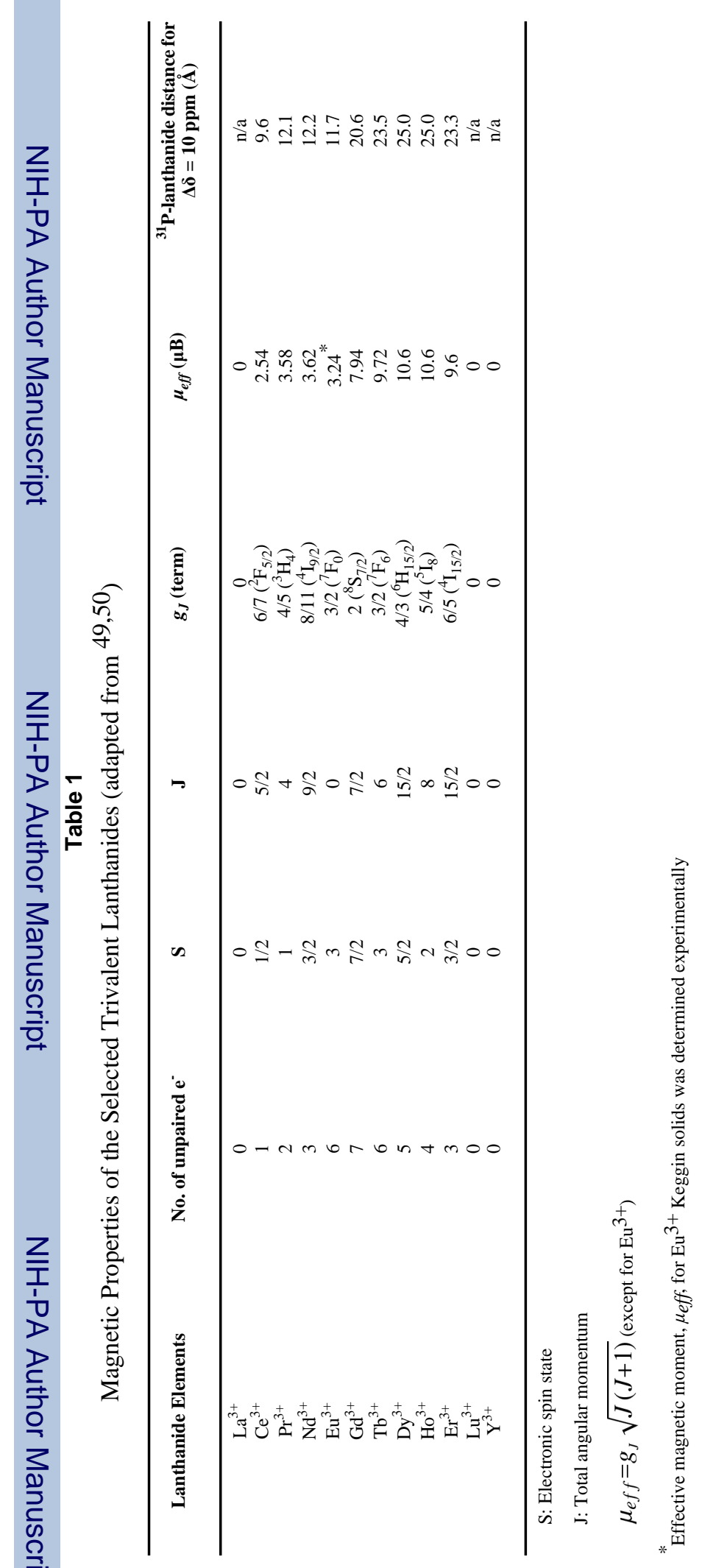




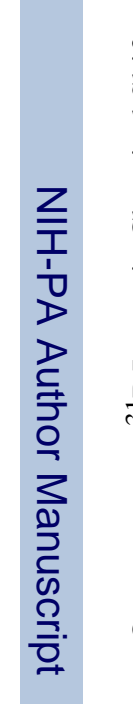

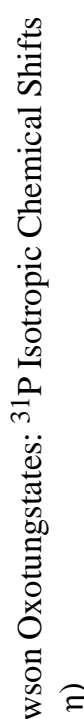

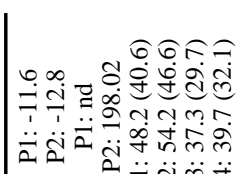

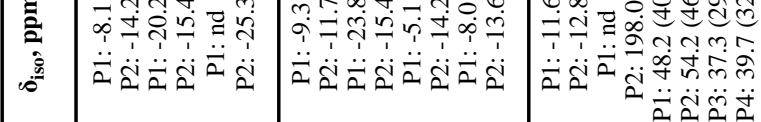

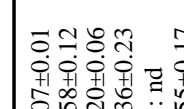

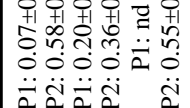

के

远范茫

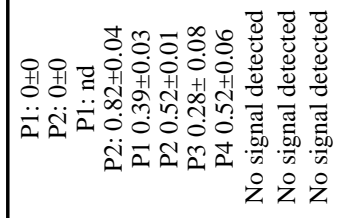

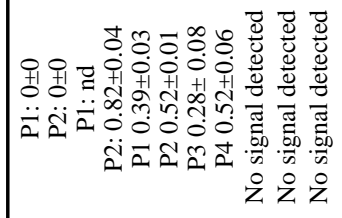

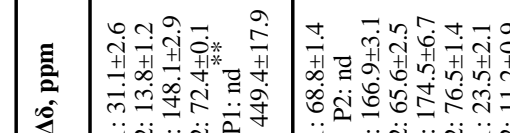

tin केष

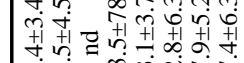

z
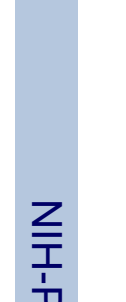

ì

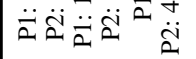

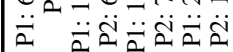

तิง

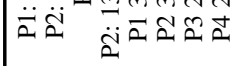

D $\frac{0}{\circ}$

으

อ

के

웡

妾

के

를

(1)

$\frac{\bar{g}}{2}$

욤

च

营

ᄒ

过

过

옴

후

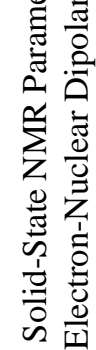

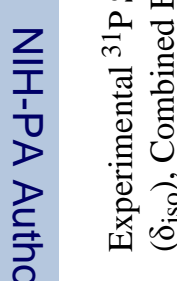

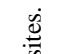




\section{Table 3}

Calculated Electronic-Nuclear $\left(\mathrm{Ln}^{31} \mathrm{P}\right)$ Dipolar Interaction in Crystallographically Characterized LanthanideSubstituted Wells-Dawson Oxotungstates II, III, IV, V, and in the Tetrameric Keggin Oxotungstates IX and X. Paramagnetic Centers within $100 \AA$ were included in the calculations

\begin{tabular}{|c|c|c|c|c|}
\hline & Compounds & Family & $\Delta \delta, \mathbf{p p m}$ & $\eta$ \\
\hline III & $\begin{array}{l}\mathrm{K}_{14}\left(\mathrm{H}_{3} \mathrm{O}\right)_{3}\left[\mathrm{Nd}\left(\alpha_{1}-\mathrm{P}_{2} \mathrm{~W}_{17} \mathrm{O}_{61}\right)_{2}\right] \cdot 4 \mathrm{KCl} \cdot 64 \mathrm{H}_{2} \mathrm{O} \\
\mathrm{K}_{14}\left(\mathrm{H}_{3} \mathrm{O}\right)_{3}\left[\operatorname{Er}\left(\alpha_{1}-\mathrm{P}_{2} \mathrm{~W}_{17} \mathrm{O}_{61}\right)_{2}\right] \cdot 4 \mathrm{KCl} \cdot 64 \mathrm{H}_{2} \mathrm{O} *\end{array}$ & Wells-Dawson & $\begin{array}{l}\text { P1: } 171.0 \\
\text { P2: } 69.9 \\
\text { P1: } 1295.5 \\
\text { P2: } 528.5\end{array}$ & $\begin{array}{l}\text { P1: } 0.05 \\
\text { P2: } 0.08 \\
\text { P1: } 0.05 \\
\text { P2: } 0.10\end{array}$ \\
\hline IV & $\begin{array}{l}\mathrm{K}_{13}\left(\mathrm{H}_{3} \mathrm{O}\right)\left[\mathrm{Ce}\left(\mathrm{H}_{2} \mathrm{O}\right)_{4}\left(\alpha_{2}-\mathrm{P}_{2} \mathrm{~W}_{17} \mathrm{O}_{61}\right)\right]_{2} \cdot 2 \mathrm{KCl} \cdot \mathrm{nH}_{2} \mathrm{O} \\
\mathrm{K}_{13}\left(\mathrm{H}_{3} \mathrm{O}\right)\left[\mathrm{Nd}\left(\mathrm{H}_{2} \mathrm{O}\right)_{3}\left(\alpha_{2}-\mathrm{P}_{2} \mathrm{~W}_{17} \mathrm{O}_{61}\right)\right]_{2} \cdot 2 \mathrm{KCl} \cdot \mathrm{nH}_{2} \mathrm{O}\end{array}$ & Wells-Dawson & $\begin{array}{l}\text { P1: } 88.6 \\
\text { P2: } 8.3 \\
\text { P1: } 188.2 \\
\text { P2: } 45.8\end{array}$ & $\begin{array}{l}\text { P1: } 0.13 \\
\text { P2: } 0.44 \\
\text { P1: } 0.26 \\
\text { P2: } 0.14\end{array}$ \\
\hline $\begin{array}{l}\mathbf{I X} \\
\mathbf{X}\end{array}$ & $\begin{array}{l}\left.\mathrm{Na}_{8} \mathrm{~K}_{5}\left(\mathrm{H}_{3} \mathrm{O}\right)_{19} \mathrm{Cl}_{10}\left[\left(\mathrm{Er}_{2} \mathrm{PW}_{10} \mathrm{O}_{38}\right)_{4} \mathrm{~W}_{3} \mathrm{O}_{8}\left(\mathrm{H}_{2} \mathrm{O}\right)_{2}(\mathrm{OH})_{4}\right)\right] \cdot\left(\mathrm{CH}_{3} \mathrm{OH}\right) \cdot 32 \mathrm{H}_{2} \mathrm{O} * \\
\left(\mathrm{NH}_{4}\right)_{22}\left[\left(\mathrm{Eu}_{2} \mathrm{PW}_{10} \mathrm{O}_{38}\right)_{4}\left(\mathrm{~W}_{3} \mathrm{O}_{8}\left(\mathrm{H}_{2} \mathrm{O}\right)_{2}(\mathrm{OH})_{4}\right)\right] \cdot 44 \mathrm{H}_{2} \mathrm{O}\end{array}$ & Keggin & $\begin{array}{l}\text { P1: } 2765 \\
\text { P2: } 2356 \\
\text { P1: } 318.2 \\
\text { P2: } 312.3 \\
\text { P3: } 282.3 \\
\text { P4: } 277.0\end{array}$ & $\begin{array}{l}\text { P1: } 0.35 \\
\text { P2: } 0.58 \\
\text { P1: } 0.48 \\
\text { P2: } 0.49 \\
\text { P3: } 0.41 \\
\text { P4: } 0.80\end{array}$ \\
\hline
\end{tabular}




\section{Table 4}

Ln- ${ }^{31} \mathrm{P}$ Internuclear Distances Determined from X-ray Diffraction and Extracted from the Electron-Nuclear Dipolar Couplings (under the Assumption of a Single Electron-Nuclear Spin Pair)

\begin{tabular}{|c|c|c|c|c|}
\hline & Compounds & Family & X-ray distance, $\AA$ & NMR distance, $\AA$ \\
\hline III & $\begin{array}{l}\mathrm{K}_{14}\left(\mathrm{H}_{3} \mathrm{O}\right)_{3}\left[\mathrm{Nd}\left(\alpha_{1}-\mathrm{P}_{2} \mathrm{~W}_{17} \mathrm{O}_{61}\right)_{2}\right] \cdot 4 \mathrm{KCl} \cdot 64 \mathrm{H} 2 \mathrm{O} \\
\mathrm{K}_{14}\left(\mathrm{H}_{3} \mathrm{O}\right)_{3}\left[\operatorname{Er}\left(\alpha_{1}-\mathrm{P}_{2} \mathrm{~W}_{17} \mathrm{O}_{61}\right)_{2}\right] \cdot 4 \mathrm{KCl} \cdot 64 \mathrm{H}_{2} \mathrm{O}^{*}\end{array}$ & Wells-Dawson & $\begin{array}{l}\text { P1: } 4.67 \\
\text { P2: } 6.23 \\
\text { P1: } 4.56 \\
\text { P2: } 6.03\end{array}$ & $\begin{array}{l}\text { P1: } 4.96 \\
\text { P2: } 6.30 \\
\text { P1:nd } \\
\text { P2: } 6.56\end{array}$ \\
\hline IV & 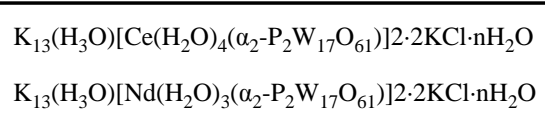 & Wells-Dawson & $\begin{array}{l}\text { P1: } 4.66 \\
\text { P2: } 8.27 \\
\text { P1: } 4.44 \\
\text { P2: } 8.09\end{array}$ & $\begin{array}{l}\text { P1:5.06 } \\
\text { P2: nd } \\
\text { P1:4.77 } \\
\text { P2: } 6.51\end{array}$ \\
\hline
\end{tabular}

